\title{
Pharmacological Approaches to Delaying Disability Progression in Patients with Multiple Sclerosis
}

\author{
Heinz Wiendl ${ }^{1}$ - Sven G. Meuth ${ }^{1}$
}

Published online: 2 June 2015

(c) The Author(s) 2015. This article is published with open access at Springerlink.com

\begin{abstract}
In individuals with multiple sclerosis, physical and cognitive disability progression are clinical and pathophysiological hallmarks of the disease. Despite shortcomings, particularly in capturing cognitive deficits, the Expanded Disability Status Scale is the assessment of disability progression most widely used in clinical trials. Here, we review treatment effects on disability that have been reported in large clinical trials of disease-modifying treatment, both among patients with relapsing-remitting disease and among those with progressive disease. However, direct comparisons are confounded to some degree by the lack of consistency in assessment of disability progression across trials. Confirmed disability progression (CDP) is a more robust measure when performed over a 6-month than a 3-month interval, and reduction in the risk of 6-month CDP in phase III trials provides good evidence for the beneficial effects on disability of several high-efficacy treatments for relapsing-remitting disease. It is also becoming increasingly clear that therapies effective in relapsing-remitting disease have little impact on the course of progressive disease. Given that the pathophysiological mechanisms, which lead to the long-term accrual of physical and cognitive deficits, are evident at the earliest stages of disease, it remains a matter of debate whether the most effective therapies are administered early enough to afford patients the best long-term outcomes.
\end{abstract}

Heinz Wiendl

heinz.wiendl@ukmuenster.de

1 Department of Neurology, University of Münster, Albert-Schweitzer-Campus 1, Building A1, 48149 Münster, Germany

\section{Key Points}

Several high-efficacy immune therapies can reduce the risk of disability progression in relapsingremitting multiple sclerosis.

A standard definition of disability progression would facilitate comparative evaluation of therapies.

In relapsing multiple sclerosis, and potentially in certain progressive phenotypes, the best outcomes may be afforded by early treatment with the most effective immune therapies.

\section{Introduction}

Disability progression is a key clinical outcome in patients with multiple sclerosis (MS) that was originally assessed using the Disability Status Scale (DSS) [1]. The DSS was superseded by an expanded version of the scale [Expanded DSS (EDSS)], with which worsening disability can be scored in 0.5-point increments from 0 (normal neurological status) to 10 (death due to MS) [2]. Without treatment, patients with MS accrue moderate levels of disability (DSS score of 3) on average within 8 years of diagnosis, and need assistance walking (DSS score of 6) within 15 years of diagnosis [3]. Compounded by the unpredictable and debilitating nature of relapses experienced by many patients early in the disease course, even moderate levels of disability can be highly disruptive to normal living. A retrospective analysis of the Danish MS patient registry found that the median time from onset of MS to retirement (receipt of an early pension) was 10 years, compared with 
24 years among matched control individuals [4]. A study of patients in nine European countries found an unemployment rate of $50 \%$ among patients of working age with an EDSS score of 3.0, and also found a steady decline in utility score [calculated from the 5-dimension European Quality of Life (EuroQol) questionnaire] with increasing EDSS score [5].

The EDSS focuses mainly on motor function and ambulation, but captures cognitive decline poorly and has several other shortcomings [6]: ambiguity in the original rules for scoring affects reproducibility among raters, especially in the range $0-4.0$ [7-10]; the scale is non-linear (i.e. the clinical importance of a 1-point increase varies depending on initial score) and a patient's rate of progression through the scale also depends on baseline score [11]. This situation prompted development of the MS Functional Composite (MSFC), which assesses disability progression based on dexterity (Nine-Hole Peg Test), ambulation (Timed 25-Foot Walk Test) and cognitive function [Paced Auditory Serial Addition Test (PASAT)] [12, 13]. The MSFC has advantages over the EDSS, and is included as an endpoint in many studies, but it also has limitations: $z$ scores (the summary score from the three components) are difficult to interpret; learning effects can skew PASAT on repeated use; and assessment of visual impairment is excluded [14].

Here, we review evidence for the potential of diseasemodifying treatments (DMTs) to delay disability progression in patients with MS. We summarize disability data from all completed phase III trials of both approved and experimental therapies in patients with all forms of MS, grouping treatments by route of administration. Disability data from phase II trials are also reported, and a number of failed or inconclusive trials are listed, although these have been reviewed extensively elsewhere $[15,16]$. The EDSS is the assessment most commonly used in MS trials (relatively few report changes in MSFC score), therefore we focus on measures related to EDSS score, such as confirmed disability progression (CDP), which is usually based on changes in the score sustained over 3 or 6 months; of these, 6-month CDP is the more robust indicator of permanent disability progression $[17,18]$. Generally, CDP is defined as a 1.0-point increase if the EDSS score is less than 5.5 at baseline (sometimes a 1.5-point increase if EDSS score is 0), and as a 0.5-point increase if the baseline EDSS score is at least 5.5, but variations in these criteria are noted.

Reflecting the current treatment landscape, the majority of trials are in patients with relapsing-remitting MS (RRMS), rather than clinically isolated syndrome (CIS), primary progressive MS (PPMS) or secondary progressive MS (SPMS), and although used in the trials discussed here, some of this nomenclature has been recently superseded [19]. Trials are therefore grouped as pertaining to relapsing-remitting or to progressive disease.

\section{Therapies in Patients with Relapsing-Remitting MS}

Summary trial information and baseline characteristics are shown in Table 1 and disability outcomes from each trial are provided in Table 2.

\subsection{Approved Oral Therapies}

\subsubsection{Fingolimod}

Fingolimod (Gilenya ${ }^{\circledR}$, Novartis) was the first oral therapy used in the treatment of patients with RRMS, and has shown evidence of reducing disability progression in phase III trials [2022]. It is approved in the USA for treating patients with relapsing forms of MS [23], and in the EU either as first-line therapy in patients with rapidly evolving severe RRMS or as second-line treatment in patients with RRMS and high disease activity despite treatment with at least one DMT [24]. Compared with placebo, fingolimod $0.5 \mathrm{mg}$ (approved daily dose) reduced the respective risk of 3-month and 6-month CDP by 30 and $37 \%$, respectively, in FREEDOMS ( $p<0.05$, both) [20], but had a non-significant effect on CDP in FREEDOMS II [21]. The finding in FREEDOMS II was attributed to high variability in disability progression among patients with baseline EDSS scores of 0 , and an exploratory analysis that excluded these patients found a significant reduction in the risk of 3-month CDP with fingolimod $0.5 \mathrm{mg}$ versus placebo [hazard ratio (HR), 0.70; $95 \%$ confidence interval (CI): 0.50, 0.98; $p=0.040]$. Proportionately more patients had 3-month CDP in FREEDOMS II than in FREEDOMS, and the proportions with 6-month CDP were similar in both studies. A relatively small proportion of patients had 3-month CDP in the 1-year TRANSFORMS trial, and neither the $29 \%$ reduction in risk of 3-month CDP with fingolimod $0.5 \mathrm{mg}$ versus intramuscular interferon (IFN) beta-1a, nor the between-group difference in EDSS score reached significance [22, 24]. However, changes in MSFC scores were beneficial on fingolimod $0.5 \mathrm{mg}$ compared with controls in all three trials [20-22].

\subsubsection{Teriflunomide}

Teriflunomide (Aubagio ${ }^{\circledR}$, Genzyme) was the second oral drug approved in both the EU and the USA for use in adults with RRMS [25, 26]. Two pivotal placebo-controlled, phase III trials of teriflunomide have been conducted in patients with RRMS (TEMSO [27] and TOWER [28]) and another trial in CIS (TOPIC [29]). In the 2-year TEMSO trial, patients receiving teriflunomide $14 \mathrm{mg}$ had a $30 \%$ reduction in risk of 3-month CDP compared with those receiving placebo $(p<0.05)$ [27], and at the 14-mg dose in TOWER there was a $32 \%$ risk reduction in time to sustained disability 


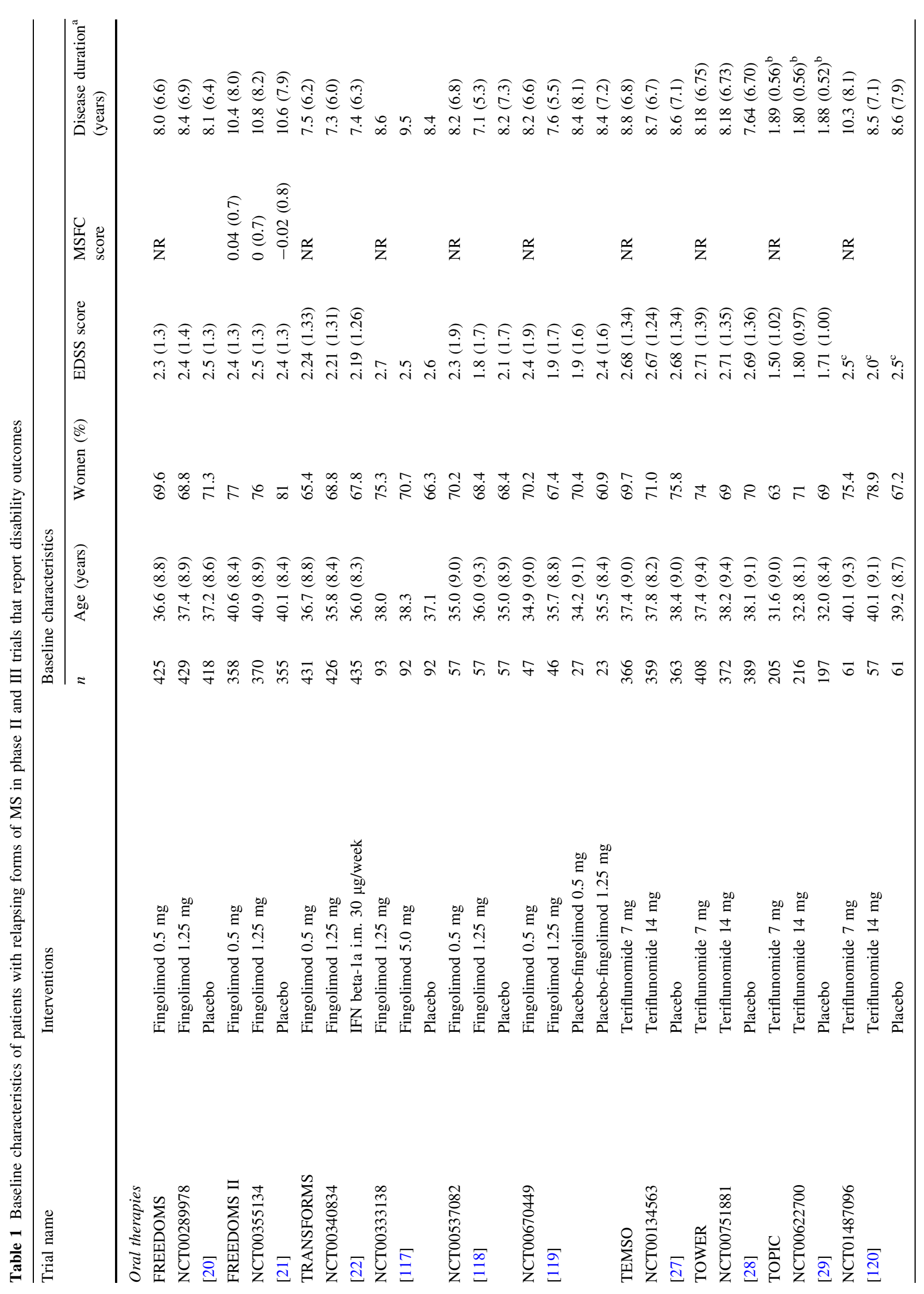




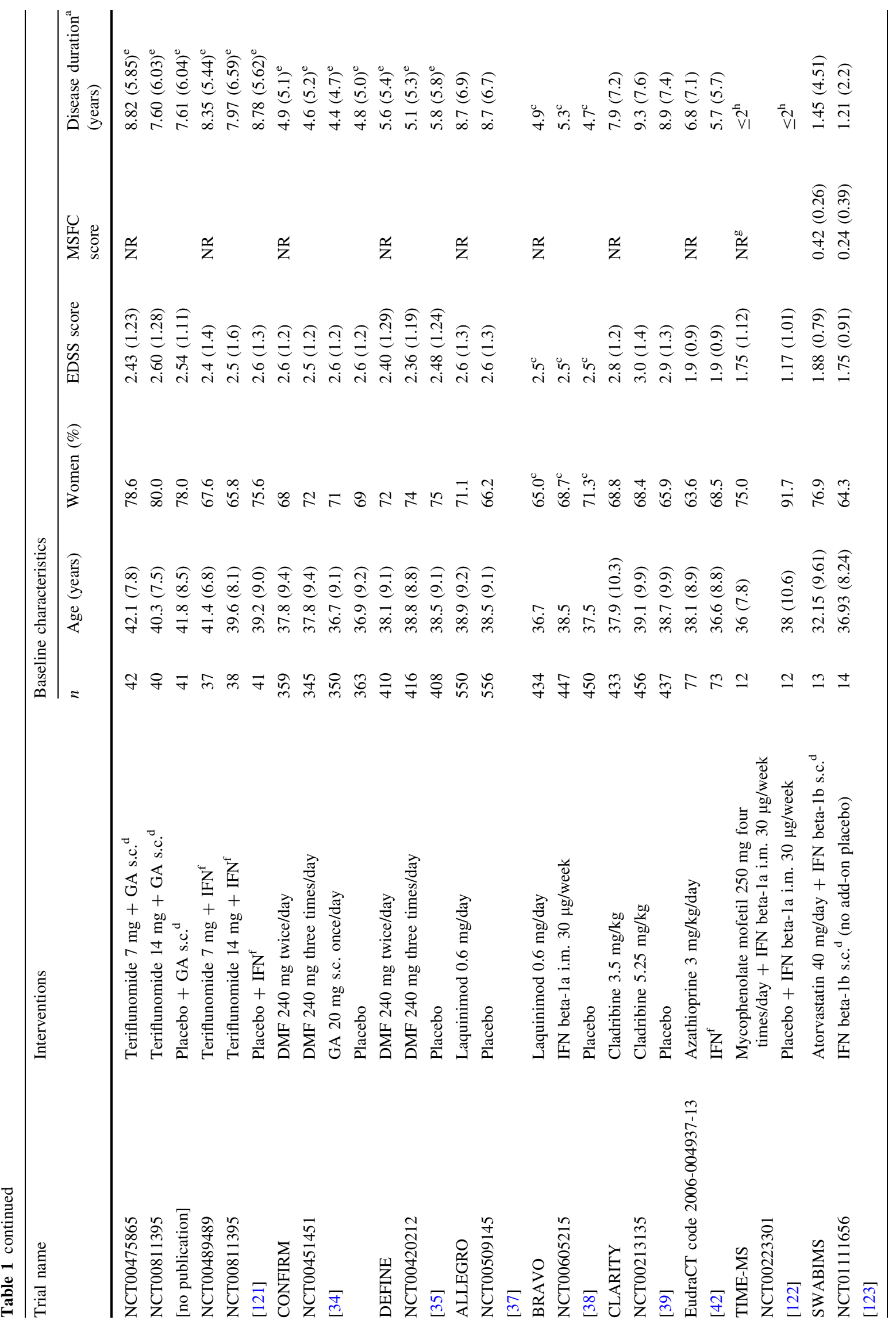




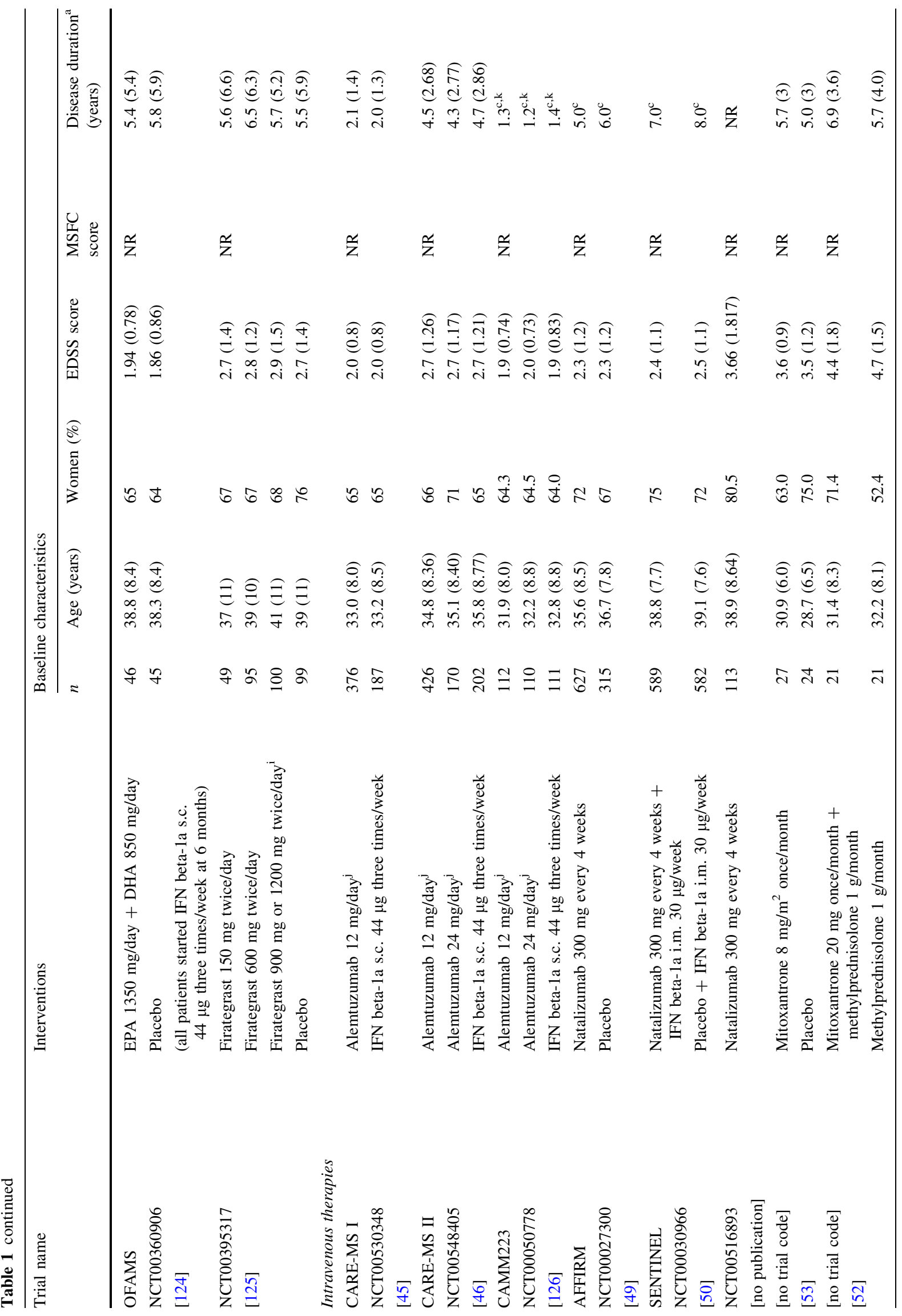




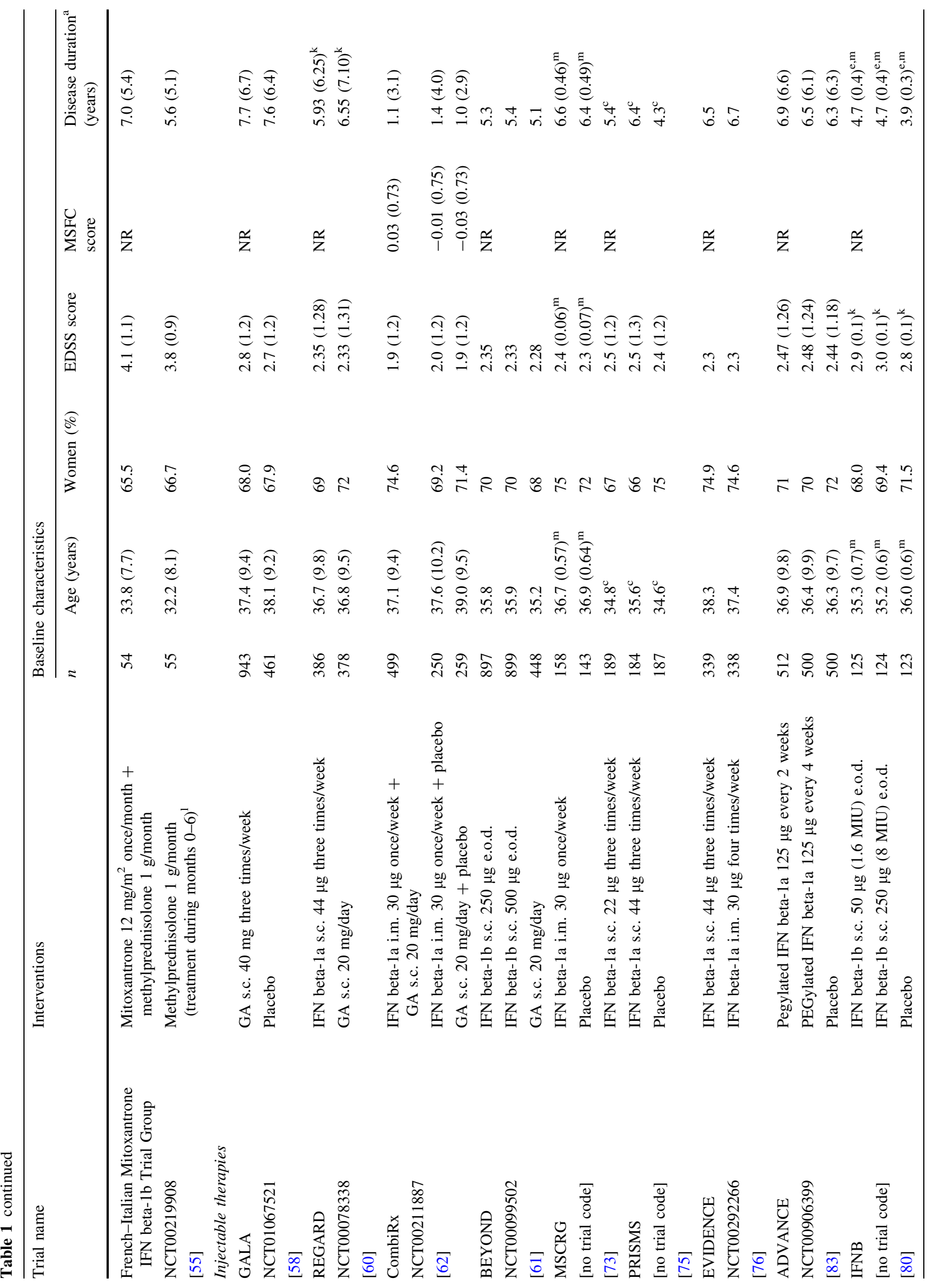




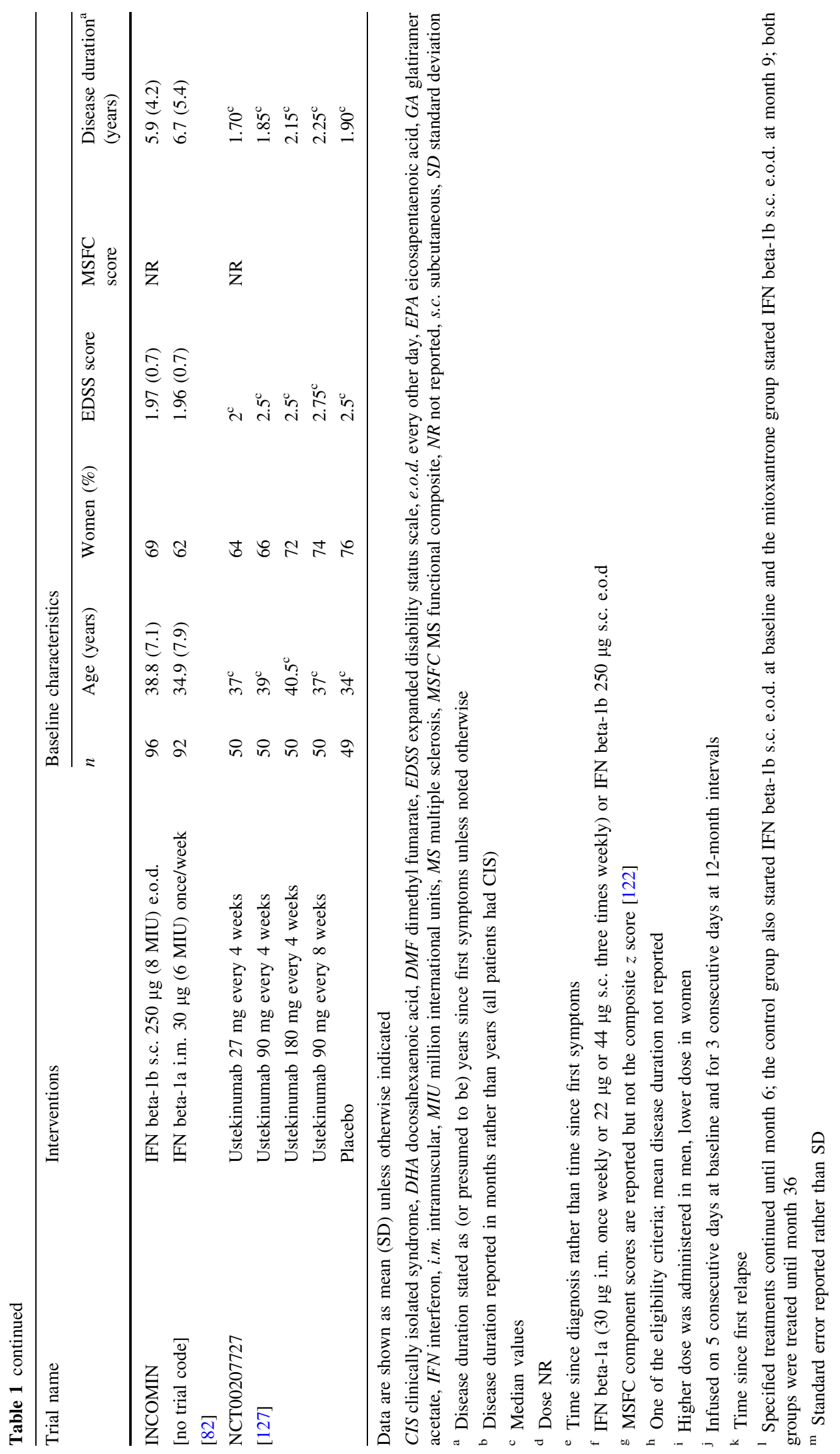




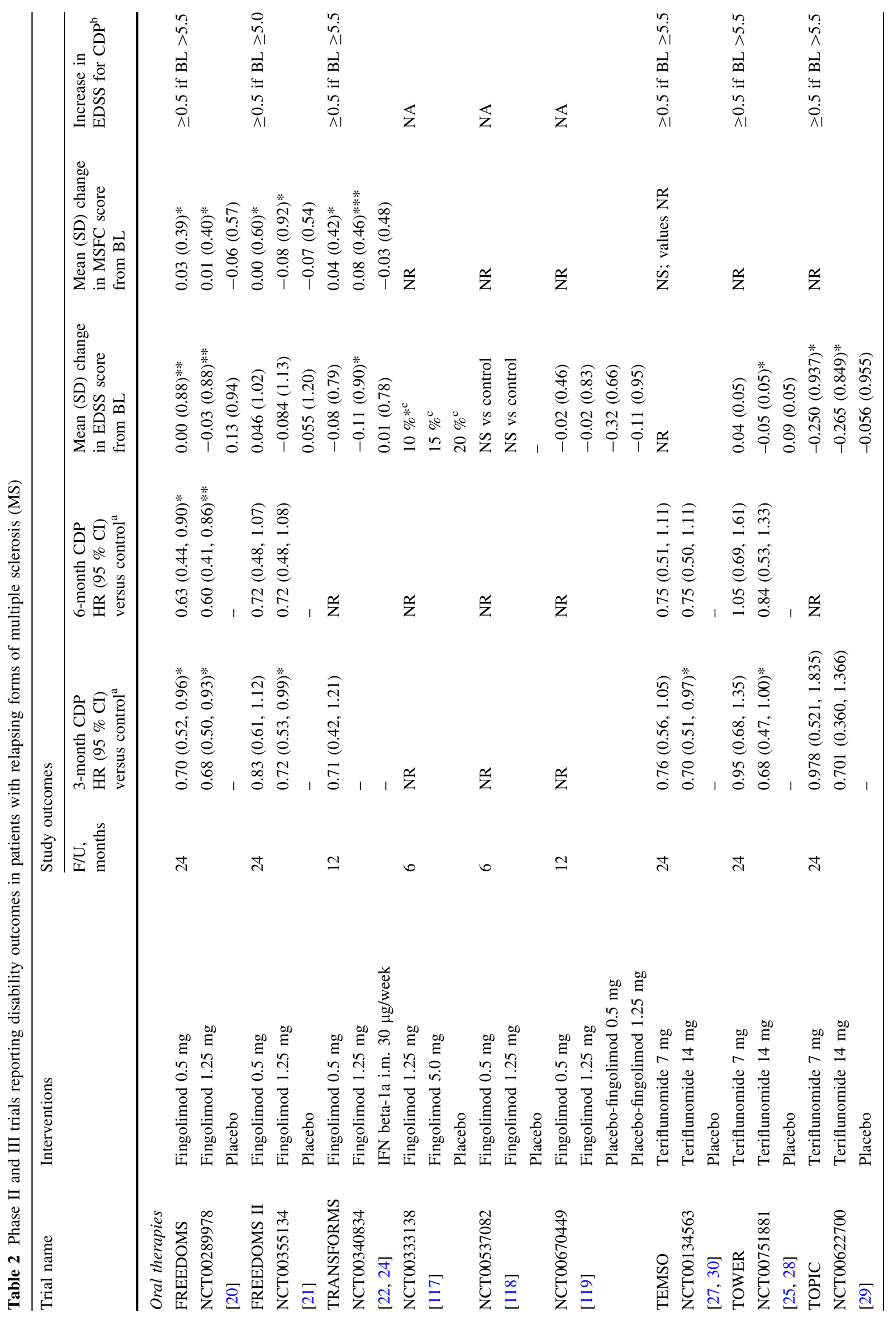




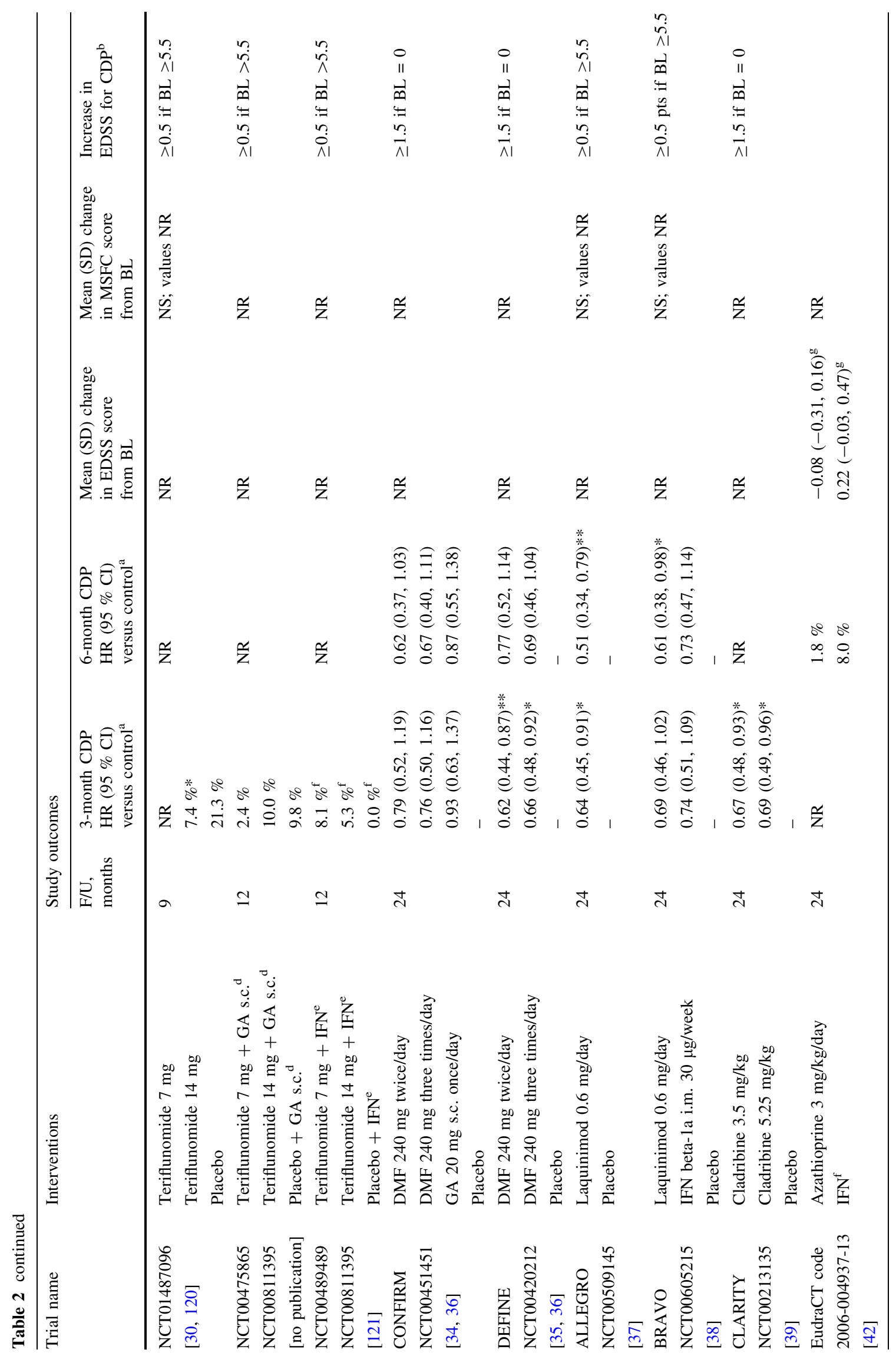




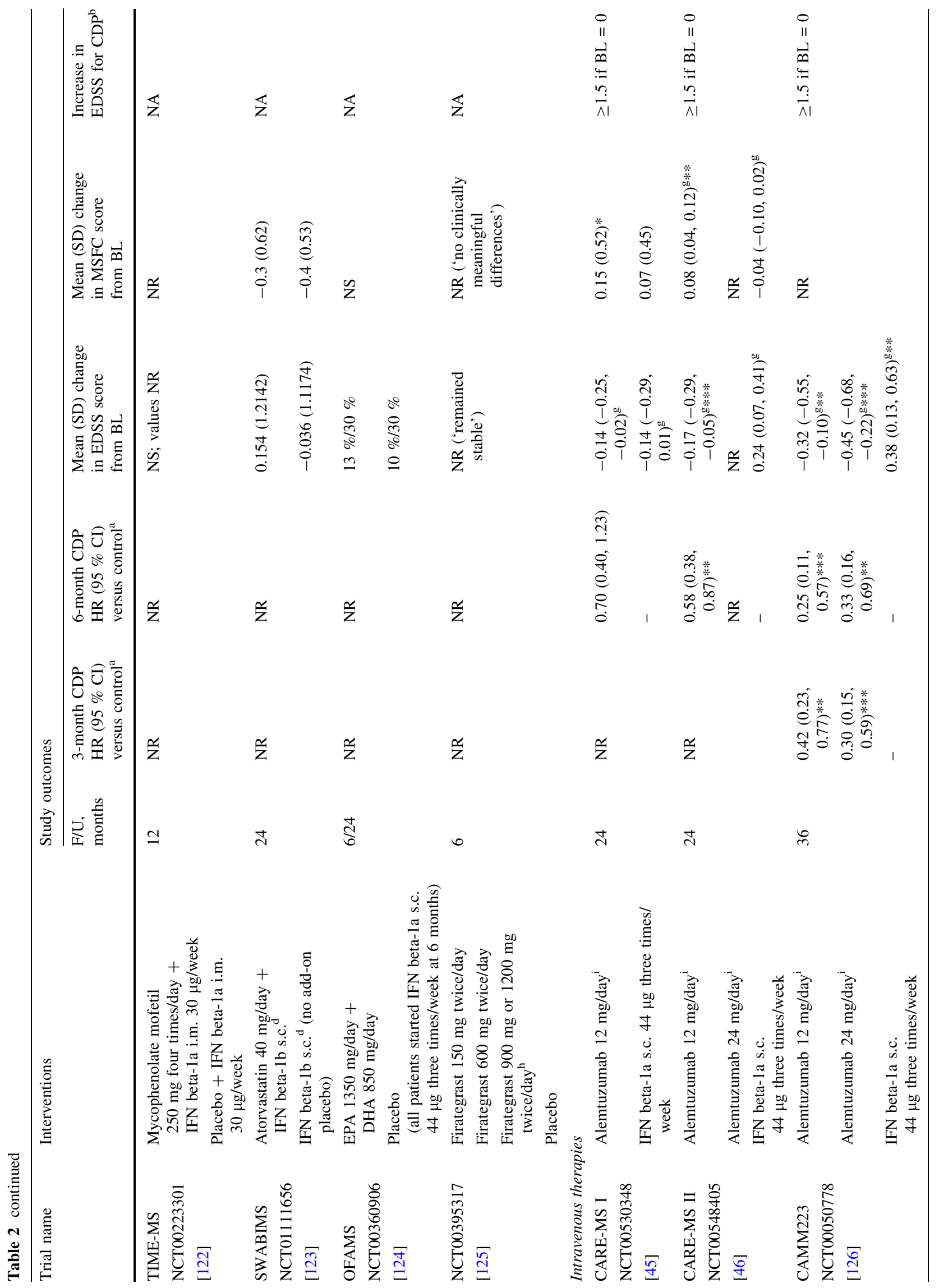




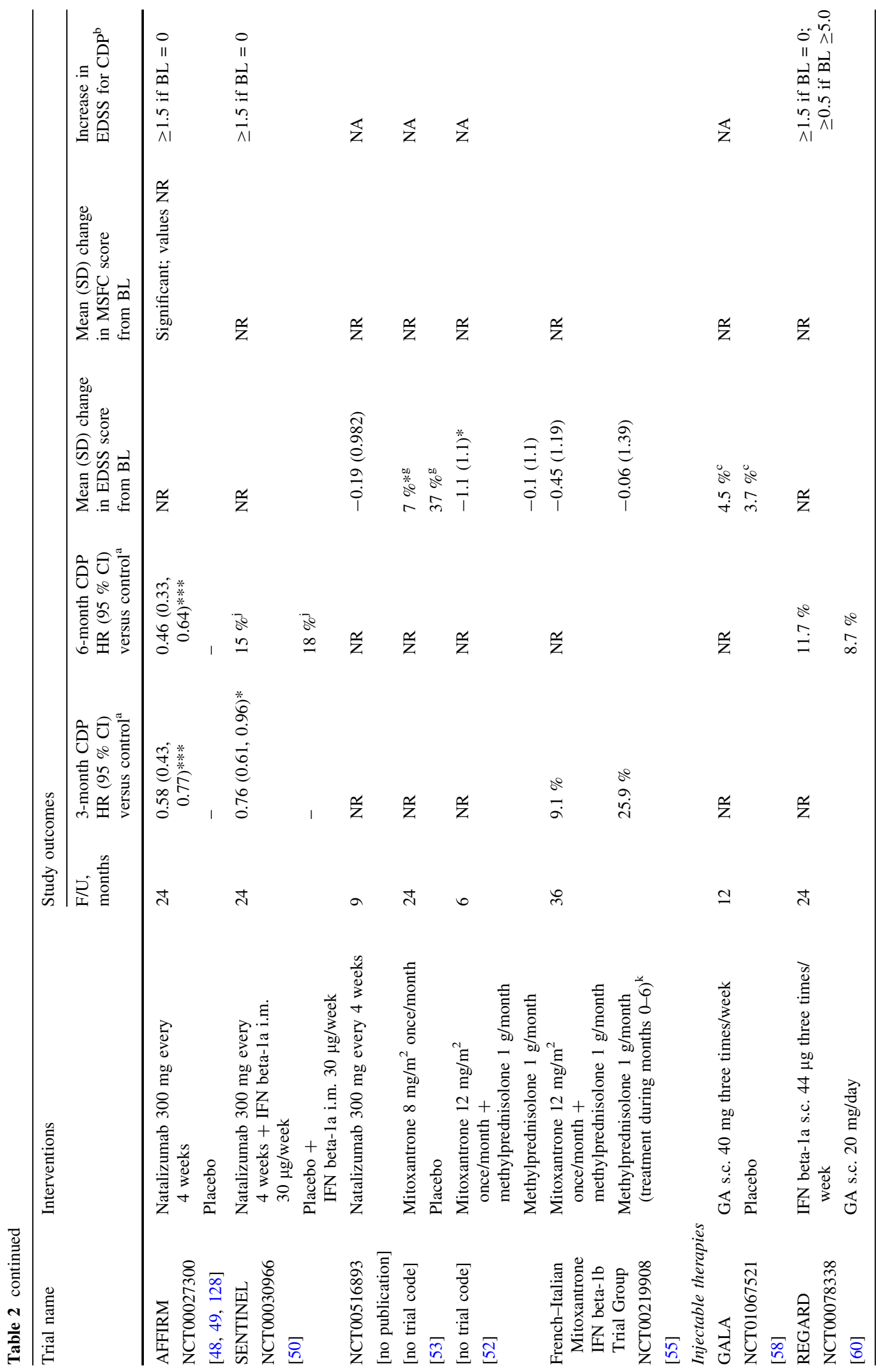




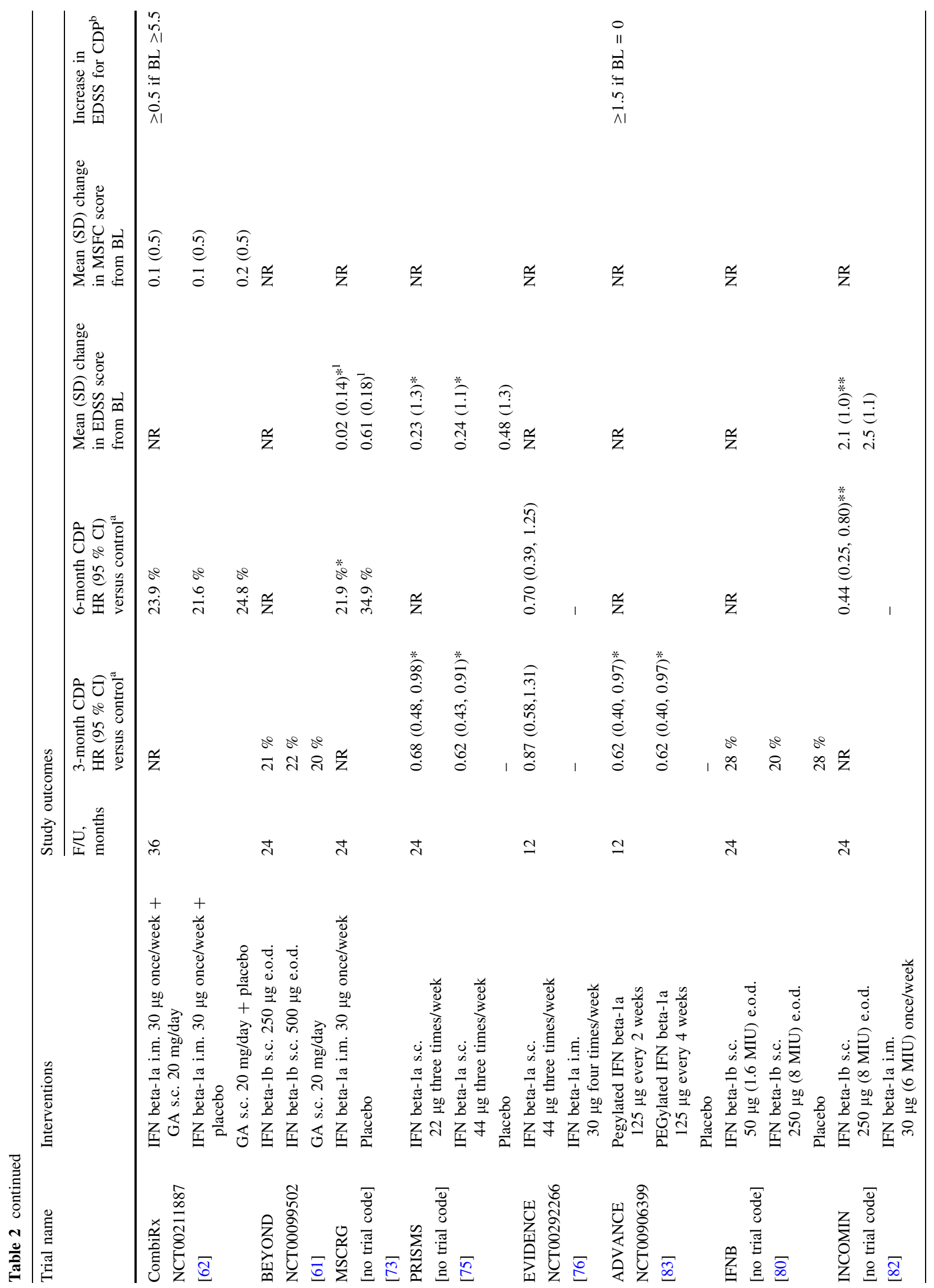




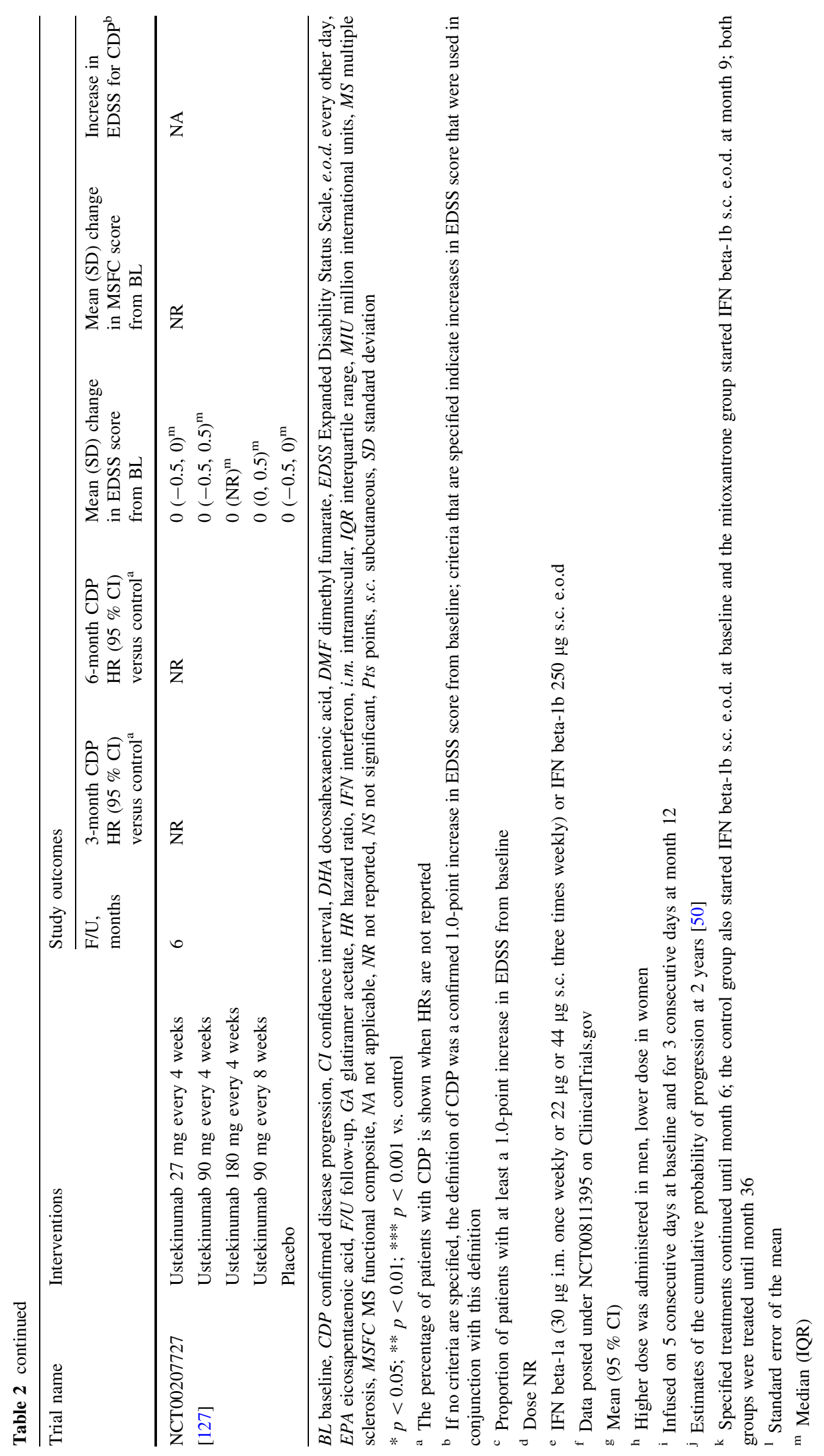


progression (a key secondary endpoint based on 3-month CDP; $p<0.05)$. Reductions in the risk of 6-month CDP failed to reach significance in either study [25] and no significant changes in MSFC were reported in TEMSO [30]. At 12 months in TOWER there was a small decrease from baseline EDSS score in the 14-mg group $(p<0.05)$ compared with the placebo group [28], and in TOPIC there was a significantly greater reduction in EDSS scores at 24 months with teriflunomide $14 \mathrm{mg}$ compared with placebo $(p<0.05)$ [29]. Reductions in 3-month CDP, however, were not significant in the TOPIC study [29], which used the same CDP criteria as TEMSO. A fourth phase III trial, TENERE, which compared teriflunomide with subcutaneous IFN beta-1a, assessed a composite endpoint of time to disease relapse or treatment discontinuation, rather than evaluating disability as a separate endpoint [31]. Accrual of at least a 0.5-point increase in EDSS score, however, was one possible criterion for disease relapse. No differences were reported for the composite endpoint comparing teriflunomide with subcutaneous IFN beta-1a.

\subsubsection{Dimethyl Fumarate}

Dimethyl fumarate (DMF; BG-12; BG00012; Tecfidera ${ }^{\circledR}$, Biogen Idec) is approved in the EU and USA for the treatment of adult patients with RRMS [32, 33]. Two 2-year, placebo-controlled phase III trials (CONFIRM [34] and DEFINE [35]) have been reported; CONFIRM also included a reference group randomized to subcutaneous glatiramer acetate (GA). In CONFIRM, reduction in risk of 3-month CDP was not significant compared with placebo, regardless of whether DMF was administered twice or three times a day [34]. In the DEFINE trial, a $38 \%$ reduction in risk of 3-month CDP was noted for the approved regimen of $240 \mathrm{mg}$ twice a day $(p<0.01)$ [35]; neither trial reported a reduction in the risk of 6-month CDP [32, 36]. Both trials used slightly more stringent criteria for CDP than were generally used elsewhere (a 1.0-point increase, or a 1.5-point increase if EDSS score is 0 at baseline) [34, 35]. Improvements in MSFC score were observed in both trials but were not statistically significant [36].

\subsection{Oral Therapies Not Currently Approved}

\subsubsection{Laquinimod}

Laquinimod $\quad$ Nerventra $^{\circledR}, \quad$ Teva), an oral immunomodulator as yet unapproved for use in patients with MS, has been compared with placebo for the treatment of RRMS in the 2-year, phase III placebo-controlled ALLEGRO [37] and BRAVO [38] trials; BRAVO also included a comparator group receiving intramuscular IFN beta-1a. Significant reductions in the risk of 6-month CDP among patients receiving laquinimod $0.6 \mathrm{mg} /$ day compared with placebo were reported in both ALLEGRO (49\%; $p<0.01)$ and BRAVO (39\%; $p<0.05)$, and the risk of 3-month CDP was also reduced in ALLEGRO $(36 \%, p<0.05)$. In BRAVO there was a non-significant $31 \%$ reduction in 3-month CDP; changes in MSFC scores from baseline were non-significant versus placebo in both studies [37, 38].

\subsubsection{Cladribine}

Cladribine (Movectro ${ }^{\circledR}$, Merck Serono), an oral therapy approved for treatment of patients with hairy cell leukemia, was evaluated in patients with MS in the phase III CLARITY [39] and ORACLE MS [40] trials; however, clinical development was suspended in 2011 pursuant to safety concerns [41] and ORACLE MS terminated before disability outcomes were assessed [40]. The 2-year CLARITY trial used the same 3-month CDP criteria as did the phase III trials of DMF (a 1.0-point increase in EDSS score from baseline, or a 1.5-point increase if EDSS score is 0 ). At both doses of cladribine tested, the risk of 3-month CDP was approximately $50 \%$ lower than with placebo $(p<0.05$, both) [39].

\subsubsection{Azathioprine}

Azathioprine has been used to treat patients with MS for over 30 years, but its use was largely superseded by the advent of IFN beta-based therapies; however, a recent trial demonstrated its non-inferiority to IFN beta in patients with RRMS, including the finding that there was no significant between-group difference in the proportion of patients with 6-month CDP [42].

\subsection{Approved Intravenous Therapies}

\subsubsection{Alemtuzumab}

Alemtuzumab [Lemtrada ${ }^{\circledR}$, Genzyme (Sanofi)] is an antiCD52 monoclonal antibody ( $\mathrm{mAb}$ ) originally indicated for second-line therapy in patients with B-cell chronic lymphocytic leukemia, that was re-licensed in the EU (2013) and in the USA (2014) for intravenous treatment of relapsing forms of MS, with active disease defined by clinical or imaging features [43, 44]. At the approved dose of $12 \mathrm{mg} /$ day for 5 days, alemtuzumab was compared with subcutaneous IFN beta-1a in the 2-year, phase III CAREMS I [45] and CARE-MS II [46] trials (some patients were also randomized to alemtuzumab $24 \mathrm{mg} /$ day in CARE-MS II, but this was discontinued following a protocol amendment designed to accelerate recruitment into the other treatment groups). Disability was a co-primary endpoint in 
both trials, defined as 6-month CDP with a 1.0-point increase in EDSS score from baseline, or a 1.5-point increase if EDSS score was 0. Compared with subcutaneous IFN beta-1a, a $42 \%$ reduction in risk of CDP was seen among patients receiving alemtuzumab in CARE-MS II $(p<0.01)$ [46], but the $30 \%$ reduction seen in CARE-MS I was not significant [45]. In CARE-MS II, the improvement in mean EDSS score $(p<0.001)$ was significant compared with that observed with subcutaneous IFN beta-1a [46], but there was no between-group difference in EDSS score in CARE-MS I [45]. Patients eligible for CARE-MS I were treatment-naïve, unlike those eligible for CARE-MS II, who had disease breakthrough on first-line IFN beta or GA. Also in CARE-MS I, a lower proportion of patients in the subcutaneous IFN beta-1a control group had 6-month CDP (11\%) [45] than in CARE-MS II (21\%) [46]. Changes in MSFC scores in both studies were significant when considered in isolation, but not when considered in the context of a pre-specified hierarchical analysis of secondary endpoints.

\subsubsection{Natalizumab}

Natalizumab (Tysabri ${ }^{\circledR}$, Biogen Idec) is a humanized anti- $\alpha 4$ integrin $\mathrm{mAb}$ approved in the USA for the treatment of relapsing forms of MS and in the EU for the treatment of rapidly evolving severe RRMS and highly active RRMS among patients with disease breakthrough on IFN beta or GA $[47,48]$. Administered intravenously at the approved dose of $300 \mathrm{mg}$ every 4 weeks, natalizumab has been tested in two 2-year, phase III trials: AFFIRM [49], which was placebocontrolled; and SENTINEL [50], in which all patients continued intramuscular IFN beta-1a after randomization to natalizumab or placebo. The rate of 3-month CDP (defined as a 1.0-point increase in EDSS score from baseline, or a 1.5point increase if EDSS score was 0) was the co-primary endpoint in both studies. Risk reductions of $42 \%$ (AFFIRM; $p<0.001$ ) and of $24 \%$ (SENTINEL; $p<0.05$ ) were demonstrated; and a $54 \%$ reduction in the risk of 6-month $\operatorname{CDP}(p<0.001)$ was reported in AFFIRM [48-50].

\subsubsection{Mitoxantrone}

Mitoxantrone (Novantrone ${ }^{\circledR}$, EMD Serono) is an antineoplastic type II topoisomerase inhibitor used to treat patients with worsening or aggressive RRMS. Not currently approved throughout the EU, it is a therapy option in Germany and is approved for use in the USA [51]. Controlled trials of mitoxantrone involving patients with RRMS or worsening RRMS include: a 6-month study in which patients received methylprednisolone with or without mitoxantrone [52]; a 1-year placebo-controlled trial with a 1-year follow-up [53]; the 2-year placebo-controlled MIMS trial [54] (please also see Sect. 3.1.1); and, more recently, a 3 -year study by the French-Italian Mitoxantrone IFN beta1b Trial Group [55], which randomized patients either to mitoxantrone and intravenous methylprednisolone monthly for 6 months followed by subcutaneous IFN beta- $1 \mathrm{~b}$ for 27 months, or to subcutaneous IFN beta- $1 \mathrm{~b}$ for 3 years combined with monthly methylprednisolone for the first 6 months. Compared with controls, mitoxantrone treatment reduced the proportion of patients with at least a 1.0-point increase in EDSS score from baseline in the 6-month study $(p<0.01)$, and reduced the risk of 3-month CDP (defined as a 1.0-point increase in EDSS score) by $30 \%(p<0.05)$ at 2 years [53], and by $65 \%$ at 3 years [55].

\subsection{Approved Injectable Therapies}

\subsubsection{Glatiramer Acetate}

Approved in the USA and EU in patients with CIS and RRMS [56, 57], GA $\left(\right.$ Copaxone $^{\circledR}$, Teva) has been evaluated in six phase III trials [34, 58-62]. It was compared with placebo in two trials (GALA in patients with RRMS [58] and PreCISe in individuals with CIS [59]), with subcutaneous IFN beta-1a in REGARD [60], was an active comparator in two trials in patients with RRMS (the placebo-controlled CONFIRM trial of DMF [34] and the BEYOND trial of subcutaneous IFN beta- $1 b$ [61]), and was evaluated in combination with intramuscular IFN beta-1a in a placebo-controlled trial in patients with RRMS (CombiRx [62]). No large trials have reported an effect of $\mathrm{GA}$ on CDP relative to control treatment.

\subsubsection{IFN beta}

The three IFN beta-based therapies are the most longstanding approved DMTs for patients with RRMS and CIS, subcutaneous IFN beta-1b originally being licensed in the USA in 1993 [63] then in the EU in 1995 [64]. Intramuscular IFN beta-1a (Avonex ${ }^{\circledR}$, Biogen Idec $[65,66]$ ), subcutaneous IFN beta-1a $\left(\right.$ Rebif $^{\circledR}$, Merck Serono [67, 68]) and subcutaneous IFN beta-1b (Extavia ${ }^{\circledR}$, Novartis [69, 70]; Betaferon ${ }^{\circledR}$, Bayer [71, 72]) have been included in at least 18 phase III trials, either as the focus of investigation $[61,62,73-82]$ or as reference compounds [22, 31, 38, 45, $46,50,55]$. In the 2-year MSCRG study, proportionately fewer patients with RRMS had 6-month CDP on intramuscular IFN beta-1a than on placebo, and time to 6-month CDP was greater than with placebo $(p=0.02)$ [73]; disability endpoints were not reported in CHAMPS in patients with CIS [74]. In the PRISMS trial, there was a smaller increase in EDSS score over 2 years in both subcutaneous IFN beta-1a dose groups than in the placebo group [75], and subcutaneous IFN beta-1a was associated 
with non-significant reductions in the risk of 3-month and 6-month CDP compared with intramuscular IFN beta-1a in EVIDENCE [76, 77]; disability endpoints were not reported in IMPROVE [78] or among patients with CIS in REFLEX [79]. In the ADVANCE study [83] of subcutaneous pegylated IFN beta-1a (Plegridy $^{\circledR}$, Biogen Idec [84]), there was a $38 \%$ lower risk of 6-month CDP $(p<0.05)$ among patients treated every 2 weeks for 2 years compared with those who received placebo in year 1 followed by treatment every 2 weeks in year 2 [85]. Finally, with subcutaneous IFN beta-1b there was a nonsignificant reduction in 3-month CDP compared with placebo in the IFNB study in patients with RRMS [80]. Generally, there were no between-group differences in disability measures at the 8-year follow-up [86] of the BENEFIT study [81], which examined the impact of delaying treatment initiation by 1 year in patients with CIS. The exception was that throughout the study period, the early-treatment group scored higher than the delayedtreatment group on PASAT $(p<0.05)$. There were no between-group differences in the proportions of patients with 3-month CDP in the BEYOND study of subcutaneous IFN beta-1b and GA [61]. These findings are somewhat contradicted by the 2-year INCOMIN study [82], in which the risk of 6-month CDP was $56 \%$ lower with subcutaneous IFN beta-1b than with intramuscular IFN beta-1a $(p<0.01)$.

\subsection{Injectable Therapies Not Currently Approved}

\subsubsection{Daclizumab High-Yield Process}

The randomized DECIDE trial compared subcutaneous daclizumab high-yield process (DAC HYP; Biogen Idec and Abbvie) with intramuscular IFN beta-1a administered over 96-144 weeks, in patients with RRMS [87]. Provisional results ahead of publication indicated no significant between-group difference in 3-month CDP [88].

\section{Therapies in Patients with Progressive Forms of MS}

Summary trial information and baseline characteristics are shown in Table 3 and disability outcomes from each trial are provided in Table 4.

\subsection{Approved Intravenous Therapies}

\subsubsection{Mitoxantrone}

Approved in Germany and the USA for the treatment of patients with SPMS and progressive relapsing MS [51], mitoxantrone $12 \mathrm{mg} / \mathrm{m}^{2}$ was associated with a small reduction in EDSS score from baseline in the 2-year placebocontrolled MIMS trial. Although interpretation is somewhat confounded by the fact that the trial was conducted in a mixed population of patients with progressive relapsing MS or SPMS, this reduction in EDSS score represented a significant treatment benefit compared with placebo $(p=$ 0.0194). Time to 3-month and to 6-month CDP (increase in EDSS score of $\geq 1$ point) was also greater in these patients than in those receiving placebo ( $p=0.03$, both) [54].

\subsection{Intravenous Therapies Not Currently Approved}

\subsubsection{Cladribine}

Intravenous cladribine has been evaluated in two phase III placebo-controlled trials in patients with progressive MS, but neither study reported values for 3-month or 6-month CDP [89, 90]. Evidence for an effect on disability progression was presented in the earlier, smaller trial $(n=48)$ [89], but no effect (based on changes in EDSS score) was seen in the subsequent larger trial of patients with PPMS $(n=48)$ or SPMS $(n=111)$ [90].

\subsubsection{Rituximab}

The OLYMPUS trial of intravenous rituximab in patients with PPMS found no effect of treatment on time to 3-month CDP. A significant delay in time to 3-month CDP was identified in planned subgroup analyses of patients with gadolinium-enhanced lesions on magnetic resonance imaging (MRI) at baseline (HR $0.41 ; p=0.007)$ and in patients aged younger than 51 years (HR 0.52; $p=0.010)$, and the effect was augmented in the subgroup with both characteristics (HR 0.33; $p=0.009$ ) [91].

\subsubsection{Dirucotide (MBP8298)}

The 2-year MAESTRO-01 trial examined the efficacy of dirucotide (MBP8298; Eli Lilly) in patients with SPMS and with human leukocyte antigen (HLA) haplotypes $\mathrm{DR} 2^{+}$or $\mathrm{DR}^{+}{ }^{+}$[92]. No effect of treatment on disability progression was seen in MAESTRO-01, leading to the termination of phase III trials MAESTRO-02 and MAESTRO-03.

\subsubsection{Intravenous Immunoglobulin}

A randomized, 2-year, placebo-controlled trial of intravenous immunoglobulin (IVIG) in a mixed population of patients with PPMS $(n=34)$ or SPMS $(n=197)$ found that time to sustained disability progression was 12 weeks longer among patients receiving treatment than in those taking placebo $(p=0.0406)$ [93]. 


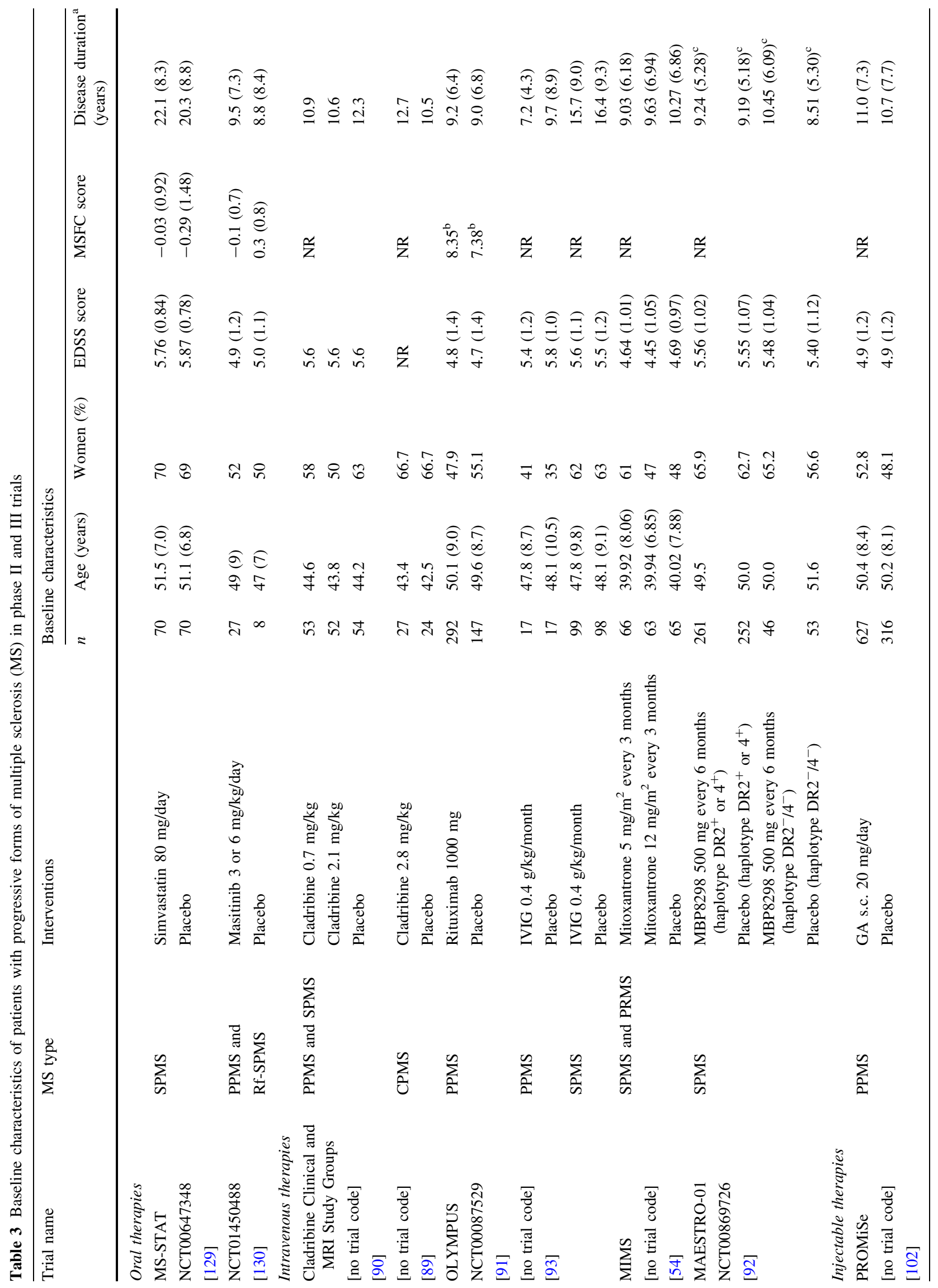




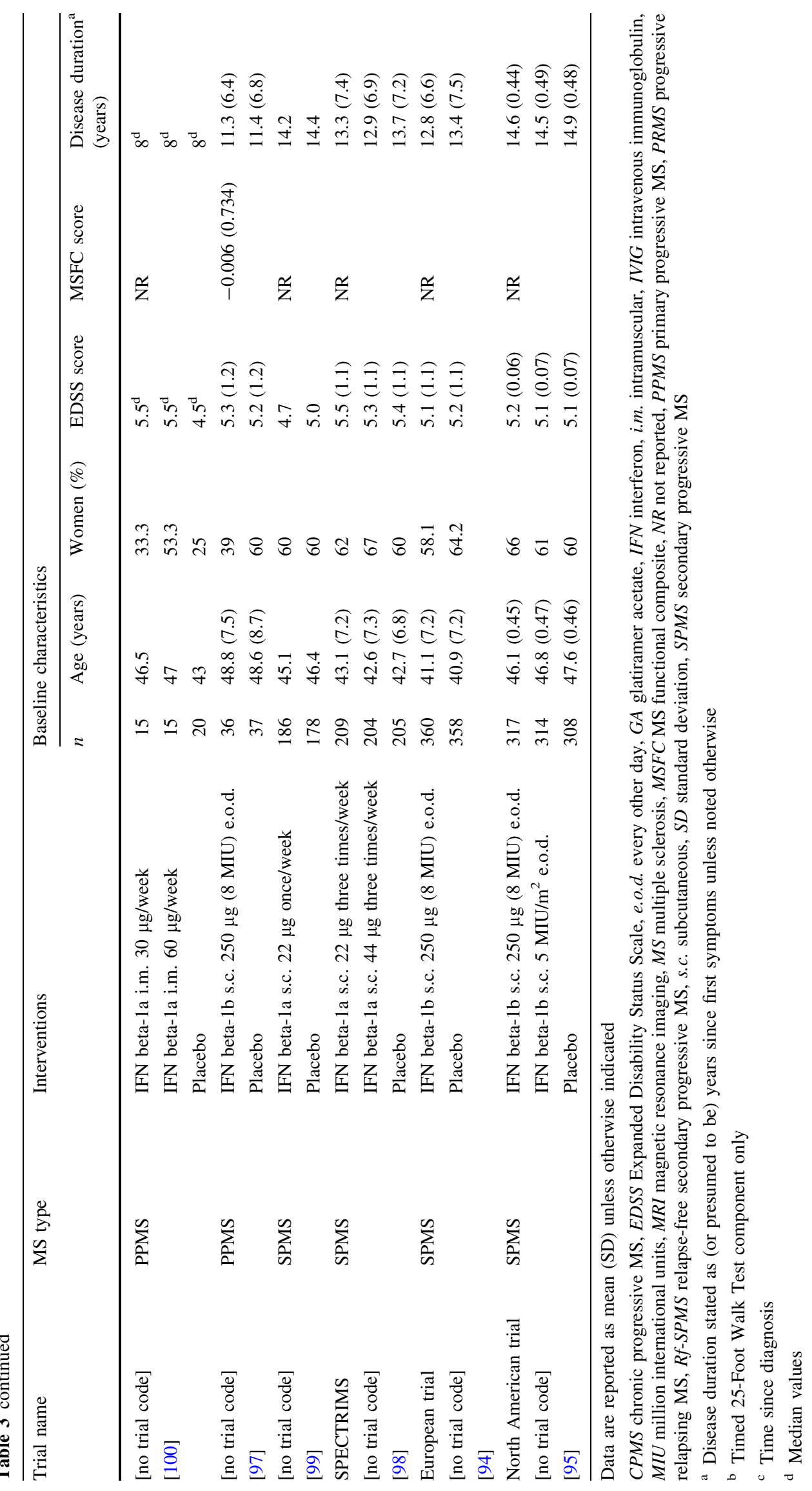




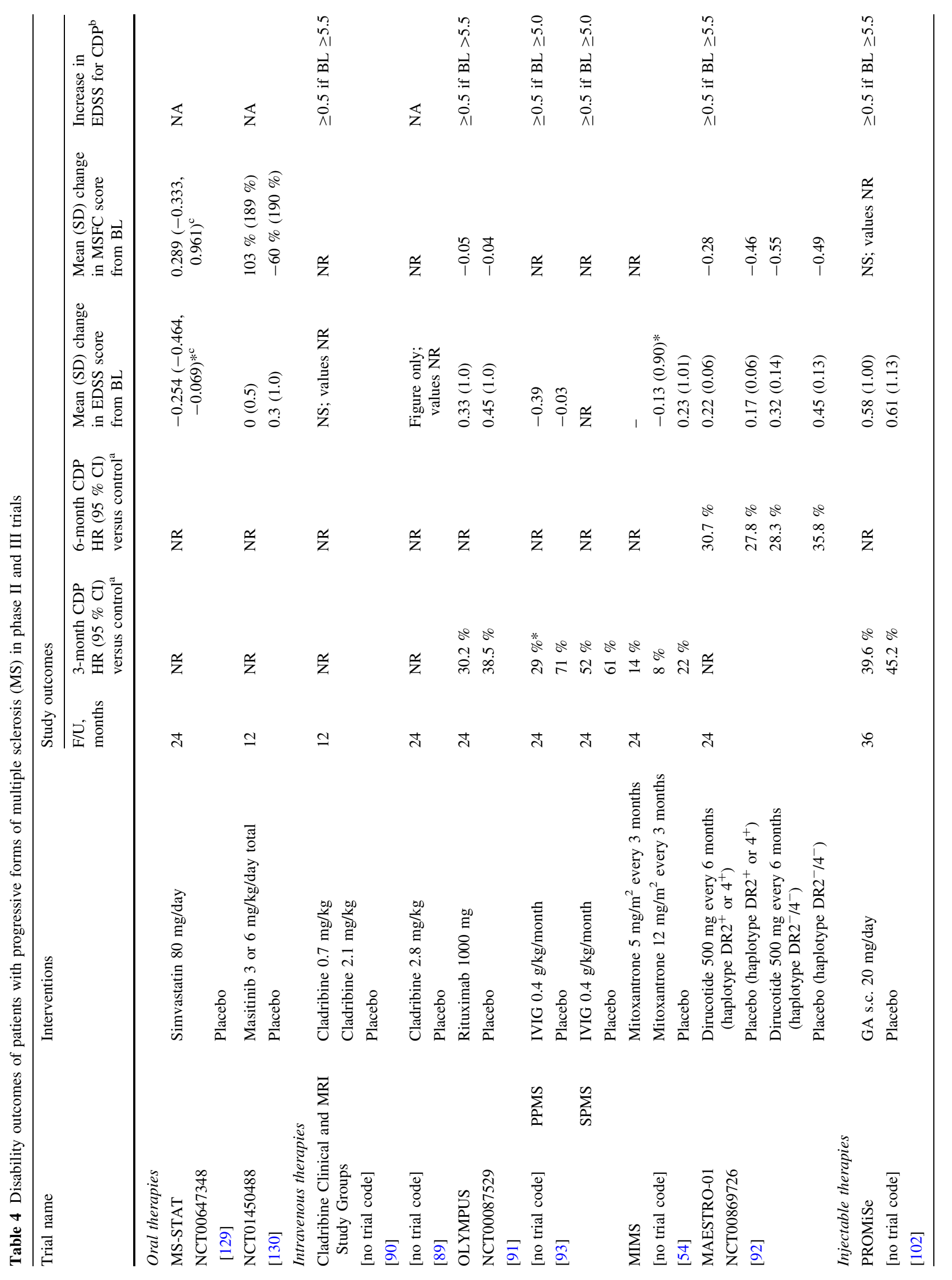




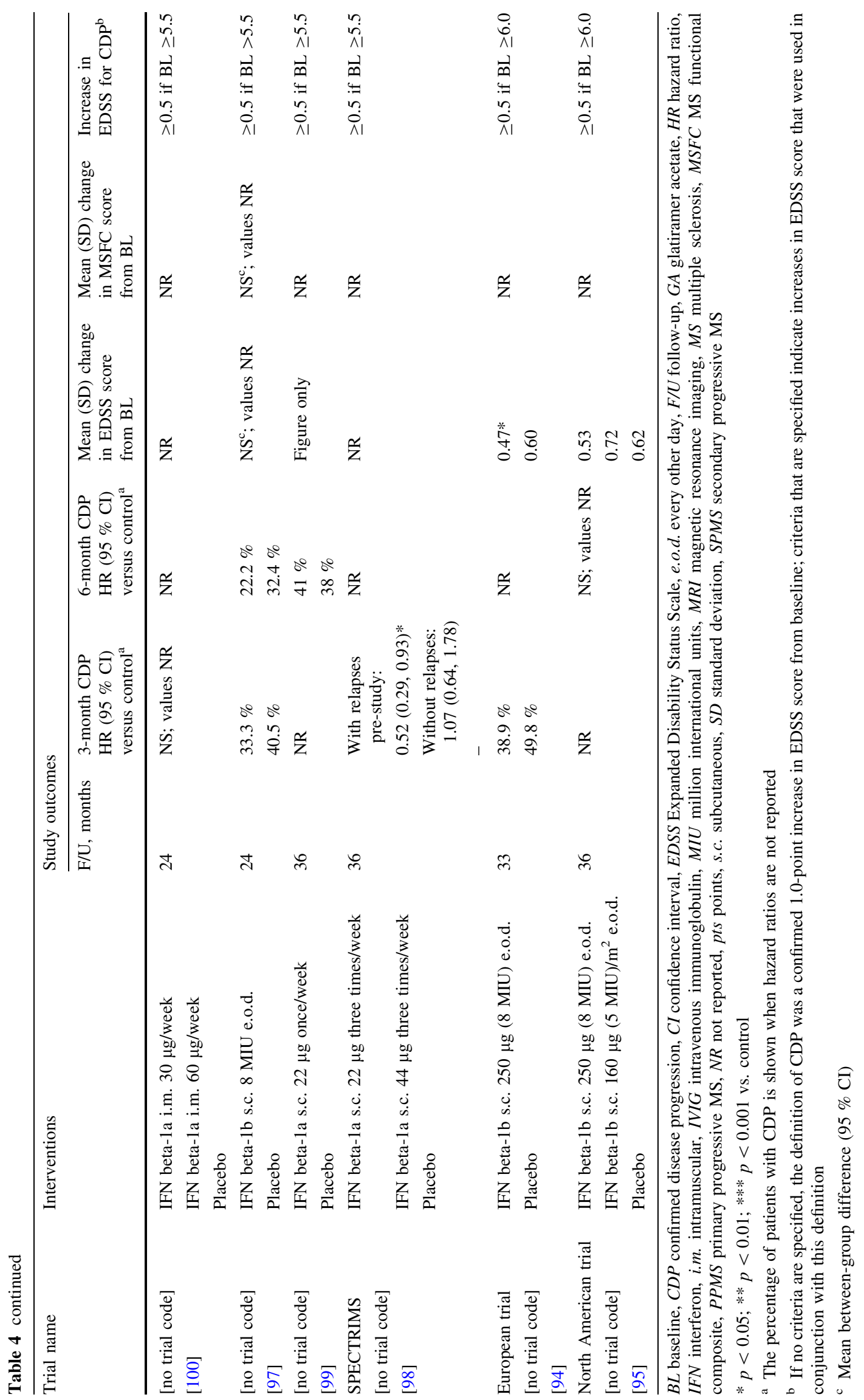




\subsection{Approved Injectable Therapies}

\subsubsection{IFN Beta}

Among the IFN beta-based therapies, only subcutaneous IFN beta-1b has received approval in the EU for treatment of progressive disease, specifically in relapsing forms of SPMS [70, 72]. Placebo-controlled trials of subcutaneous IFN beta-1b in Europe [94] and in North America [95] among patients with SPMS yielded different findings. There was a significant increase in time to 3-month CDP with treatment in the European trial compared with placebo ( $p=0.0008$ ) [94], but no effect on 6-month CDP was reported in the North American trial [95]. However, a post hoc meta-analysis of the two trial populations found an overall reduction in the risk of 6-month CDP (HR, 0.79; $95 \%$ CI: 0.66, 0.93; $p=0.0076$ ) [96]. Unfortunately, no such benefit was seen among patients with PPMS in a subsequent 2-year placebo controlled trial of subcutaneous IFN beta-1b [97]. Subcutaneous IFN beta-1a is a treatment option in Germany for relapsing forms of SPMS, although no effect on disability measures was reported in either of two 3-year placebo-controlled trials in patients with SPMS (SPECTRIMS [98]; the Nordic SPMS trial [99]); no phase III trials of subcutaneous IFN beta-1a in patients with PPMS have been reported.

\subsection{Injectable Therapies Not Currently Approved}

\subsubsection{Intramuscular IFN Beta-1a}

No improvement in time to 3-month CDP with intramuscular IFN beta-1a was seen among patients with PPMS [100], or among patients with SPMS in the 2-year IMPACT trial [101]. However, a significant improvement in MSFC scores (the primary endpoint) was seen at 2 years with intramuscular IFN beta-1a compared with placebo $(p=0.033)$.

\subsubsection{Glatiramer Acetate}

The placebo-controlled PROMiSe trial of GA in patients with PPMS was terminated when an interim analysis revealed no treatment effect on time to 3 -month $\mathrm{CDP}$, the primary outcome [102].

\section{Discussion}

The goal of DMT in patients with MS is to prevent the accrual of physical and cognitive deficits associated with disease worsening. Here, we have collected evidence of the effects of MS DMTs, with the aim of identifying those which offer the greatest benefit in mitigating disability progression. In addition to summarizing reported trial data (Tables 1, 2, 3, 4), we have listed for completeness any ongoing trials of MS DMTs and any trials that have been withdrawn or stopped (Table 5).

There are difficulties when trying to compare the efficacy of different DMTs in relation to disability outcomes. Definitions of CDP vary across trials, both in the magnitude of the change in EDSS score that constitutes progression, and in the time over which this change must be sustained. A 1.5-point change from a baseline EDSS score of zero is a more robust measure of permanent disease worsening than a 1.0-point change, because recovery from a relapse is likely in the early stages of MS. Given that recovery is also likely if assessments are made over 3 months [18], the European Medicines Agency has recommended that assessments of disability should be made at least 6 months apart [17]; however, this recommendation was made subsequent to the time when the trials reviewed here were planned.

These challenges notwithstanding, trials of fingolimod, alemtuzumab, natalizumab laquinimod and subcutaneous IFN beta-1b in patients with RRMS have demonstrated significant reductions in the risk of 6-month CDP, effect sizes being in the range $40-60 \%$ [20, 37, 38, 46, 49, 82]. A similar effect size is also implied by the proportions of patients free from 6-month CDP reported for intramuscular IFN beta-1a [73]. Patient demography at baseline was broadly similar in the phase III trials that demonstrated these treatment effects (Table 1), although the period since symptom onset was shortest in the alemtuzumab trials. Laquinimod is unusual among this group, in that its impact on disability was significant but its effect on relapse rates was modest $[37,38]$.

Evidence for mitigation of disease worsening in progressive forms of MS remains sparse, particularly in patients with PPMS. Treatment effects have been reported for mitoxantrone in a mixed population of patients with progressive disease [54], and for subcutaneous IFN beta-1b in individuals with SPMS [94, 96] but the general lack of reported values for risk reduction in trials in patients with progressive MS tends to confound comparisons. Details of the phase III INFORMS trial of fingolimod in PPMS are awaited, but it is known that the primary endpoint was not met [103].

Considerable advances have been made in the last 5 years in the treatment of relapsing MS, but the immunomodulatory nature of the majority of DMTs means that they may have little influence on the pathophysiological mechanisms associated with progressive disease [104]. Although inflammation is known to occur [105], it remains unclear whether it precedes or follows neurodegenerative tissue injury. However, there is some 
Table 5 Trials of multiple sclerosis (MS) therapies that are active but no longer recruiting, or that have been withdrawn, suspended or terminated. Trials are only listed if disability endpoints were specified

\begin{tabular}{|c|c|c|c|}
\hline Trial name & Intervention(s) & Patient group & Comment \\
\hline \multicolumn{4}{|c|}{ Active trials—oral therapies } \\
\hline $\begin{array}{l}\text { CHOLINE } \\
\text { NCT01198132 }\end{array}$ & $\begin{array}{l}\text { Cholecalciferol as add-on to subcutaneous } \\
\text { IFN beta-1a }\end{array}$ & RRMS & \\
\hline $\begin{array}{l}\text { CONTAIN } \\
\text { NCT01514370 }\end{array}$ & $\begin{array}{l}\text { Curcumin as add-on to subcutaneous IFN } \\
\text { beta-1a }\end{array}$ & Early active RMS & \\
\hline NCT00835770 & Dimethyl fumarate & RRMS & $\begin{array}{l}\text { Combined extension to CONFIRM and } \\
\text { DEFINE }\end{array}$ \\
\hline \multicolumn{4}{|l|}{ NCT00731692 } \\
\hline NCT01047319 & Laquinimod & RMS & BRAVO extension \\
\hline NCT01188811 & Lipoic acid & SPMS & \\
\hline MS-SPI & MD1003 & Spinal PMS & \\
\hline \multicolumn{4}{|l|}{ NCT02220933 } \\
\hline SUPREMES & Sunphenon & PPMS & \\
\hline NCT00799890 & & SPMS & \\
\hline NCT00803049 & Teriflunomide & RRMS & TEMSO extension \\
\hline NCT00228163 & Teriflunomide & RMS & Phase II 10-year follow-up \\
\hline $\begin{array}{l}\text { SOLAR } \\
\text { NCT01285401 }\end{array}$ & $\begin{array}{l}\text { VigantOL }{ }^{\circledR} \text { oil as add-on to subcutaneous } \\
\text { IFN beta-1a }\end{array}$ & RRMS & \\
\hline \multicolumn{4}{|c|}{ Active trials-intravenous therapies } \\
\hline \multicolumn{3}{|l|}{ NCT01116427 } & \\
\hline NCT01433250 & AIN457 (secukinumab) & RRMS & Phase II \\
\hline NCT00930553 & Alemtuzumab & RRMS & $\begin{array}{l}\text { Extension to CAMMS223, CARE-MS I } \\
\text { and CARE-MS II }\end{array}$ \\
\hline $\begin{array}{l}\text { SYNERGY } \\
\text { NCT01864148 }\end{array}$ & $\begin{array}{l}\text { BIIB033 (anti-LINGO-1) with } \\
\text { intramuscular IFN beta-1a }\end{array}$ & RMS & \\
\hline $\begin{array}{l}\text { ASCEND } \\
\text { NCT01416181 }\end{array}$ & Natalizumab & SPMS & \\
\hline NCT01416155 & Natalizumab & RRMS & Phase II Japanese study extension \\
\hline $\begin{array}{l}\text { NCT01412333 } \\
\text { NCT01247324 }\end{array}$ & $\begin{array}{l}\text { Ocrelizumab } \pm \text { subcutaneous IFN beta- } \\
\text { 1a }\end{array}$ & RRMS & \\
\hline NCT01194570 & Ocrelizumab + methylprednisolone & PPMS & \\
\hline $\begin{array}{l}\text { GATEWAY II } \\
\text { NCT01569451 }\end{array}$ & Rituximab then subcutaneous GA & $\begin{array}{l}\text { CIS } \\
\text { RMS }\end{array}$ & \\
\hline \multicolumn{4}{|c|}{ Active trials-injectable therapies } \\
\hline $\begin{array}{l}\text { DECIDE } \\
\text { NCT01064401 }\end{array}$ & Subcutaneous daclizumab + IFN beta-1a & RRMS & Pivotal phase III trial \\
\hline $\begin{array}{l}\text { SELECTED } \\
\text { NCT01051349 }\end{array}$ & Subcutaneous daclizumab & RRMS & SELECT extension \\
\hline $\begin{array}{l}\text { ATTAIN } \\
\text { NCT01332019 }\end{array}$ & Subcutaneous pegylated IFN beta-1a & RRMS & Phase III ADVANCE extension \\
\hline \multicolumn{4}{|c|}{ Withdrawn trials-oral therapies } \\
\hline NCT00296205 & High-dose cyclophosphamide & $\begin{array}{l}\text { SPMS } \\
\text { PPMS PRMS }\end{array}$ & Principal investigator changed institution \\
\hline NCT00104143 & A4i antagonist & RMS & Withdrawn before enrollment \\
\hline NCT00429442 & Simvastatin as add-on to GA & RMS & Withdrawn before enrollment \\
\hline
\end{tabular}


Table 5 continued

\begin{tabular}{|c|c|c|c|}
\hline Trial name & Intervention(s) & Patient group & Comment \\
\hline \multicolumn{4}{|c|}{ Suspended trials-intravenous therapies } \\
\hline NCT00939549 & $\begin{array}{l}\text { High-dose cyclophosphamide then } \\
\text { subcutaneous GA }\end{array}$ & RRMS & Suspended for revisions to protocol \\
\hline NCT01039103 & Nanocort in acute exacerbation & RRMS & No reason given \\
\hline \multicolumn{4}{|c|}{ Terminated trials—oral therapies } \\
\hline $\begin{array}{l}\text { TERACLES } \\
\text { NCT01252355 }\end{array}$ & Teriflunomide & RRMS & Sponsor decision, not linked to safety \\
\hline $\begin{array}{l}\text { TOFINGO } \\
\text { NCT01499667 }\end{array}$ & Fingolimod & RRMS & $\begin{array}{l}\text { Determination of natalizumab washout } \\
\text { period no longer relevant }\end{array}$ \\
\hline $\begin{array}{l}\text { RECYCLINE } \\
\text { NCT01134627 }\end{array}$ & Minocycline & RRMS & No reason recorded \\
\hline NCT00418145 & Oral (vs intravenous) steroids & RMS & Low enrollment \\
\hline NCT01516554 & Oral testosterone for fatigue & RRMS & No reason recorded \\
\hline NCT01037907 & BGC20-0134 & RRMS & Lack of efficacy \\
\hline $\begin{array}{l}\text { FLORIMS } \\
\text { NCT00623415 }\end{array}$ & Flupirtine & RRMS & \\
\hline $\begin{array}{l}\text { Memantine-MS } \\
\text { NCT00638833 }\end{array}$ & Memantine & All MS types & $\begin{array}{l}\text { Unexpected, reversible, mild-to-moderate } \\
\text { neurological impairment }\end{array}$ \\
\hline Terminated trials- & enous therapies & & \\
\hline NCT00146159 & Mitoxantrone & SPMS & No reason recorded \\
\hline NCT00219908 & Mitoxantrone & Early active RRMS & No reason recorded \\
\hline $\begin{array}{l}\text { MAESTRO-02 } \\
\text { NCT00870155 }\end{array}$ & MBP8298 & SPMS & Negative efficacy in MAESTRO-01 \\
\hline $\begin{array}{l}\text { MAESTRO-03 } \\
\text { NCT00468611 }\end{array}$ & MBP8298 & SPMS & Negative efficacy in MAESTRO-01 \\
\hline $\begin{array}{l}\text { STRATA } \\
\text { NCT00297232 }\end{array}$ & Natalizumab & RMS & No reason recorded \\
\hline Terminated trials- & able therapies & & \\
\hline $\begin{array}{l}\text { RECLAIM } \\
\text { NCT00947895 }\end{array}$ & ACTH & RRMS & Study halted after 1 year for data analysis \\
\hline $\begin{array}{l}\text { ATAMS extension } \\
\text { NCT00853762 }\end{array}$ & Atacicept & & Increased MS disease activity in ATAMS \\
\hline NCT00313976 & Subcutaneous IFN beta- $1 \mathrm{~b}$ (double dose) & SPMS & No reason recorded \\
\hline $\begin{array}{l}\text { SURPASS } \\
\text { NCT01058005 }\end{array}$ & $\begin{array}{l}\text { Subcutaneous IFN beta- } \\
1 \mathrm{a}+\text { subcutaneous GA }+ \text { natalizumab }\end{array}$ & RRMS & $\begin{array}{l}\text { Terminated by sponsor because of low } \\
\text { enrollment }\end{array}$ \\
\hline NCT00784836 & Subcutaneous IFN beta-1a $\left(\right.$ Avonex $\left.{ }^{\circledR}\right)$ & RRMS & $\begin{array}{l}\text { Terminated by sponsor for reasons } \\
\text { unrelated to safety }\end{array}$ \\
\hline
\end{tabular}

ACTH adrenocorticotrophic hormone, $C I S$ clinically isolated syndrome, $G A$ glatiramer acetate, $I F N$ interferon, $M S$ multiple sclerosis, $P P M S$ primary progressive MS, $P R M S$ progressive relapsing MS, $R M S$ relapsing MS, $R R M S$ relapsing-remitting MS, SPMS secondary progressive MS

evidence that targeting inflammatory activity may be beneficial in certain patients with progressive disease. In subgroup analyses of the OLYMPUS trial of rituximab in PPMS [91], there was a significant effect of treatment on 3-month CDP among patients with gadolinium-enhanced MRI lesions at baseline. This treatment effect was driven by the fact that disability progression was faster among patients who received placebo in this subgroup (patients with disease now classified as 'active and with progression'
[13]), than among those on placebo who were free from inflammatory activity at baseline ("not active but with progression' [13]). Age, but not disease duration, also affected outcomes in OLYMPUS: the effect of treatment on 3 -month CDP was seen in patients younger than 51 years of age, but not in older patients [91]. These findings tend to support the use of the most effective immunomodulatory therapies early in the disease course among young patients whose MS is both active and progressive. The lack of effect 
among older patients may be symptomatic of age-related functional changes in immunity, or may be because recovery mechanisms are overwhelmed once a certain level of CNS damage has been accumulated by the combined effects of disease progression and aging. Either scenario adds another layer of complexity to the problem of identifying effective treatments in progressive MS.

Figure 1 illustrates schematically how different factors might combine in different MS disease types; analogous schemes have been proposed previously [106, 107]. The relapsing-remitting disease course is initially driven by inflammation, characterized by relapses, focal demyelinated lesions and axonal loss in the central nervous system (CNS), the effects of which are to some degree mitigated by neuronal plasticity and repair mechanisms [108, 109]. Coinciding with this, diffuse neurodegenerative damage in normal-appearing white and grey matter ('underlying progression') becomes increasingly apparent as inflammatory
Fig. 1 Schematic representation of the relationship between disability progression and the underlying pathological and rescue processes during a the typical relapsing-remitting disease course, which can ultimately transition into progressive disease, and $\mathbf{b}$ the purely progressive disease course. Disease worsening in patients with relapsing MS is a consequence of incomplete recovery from what is mostly focal inflammatory disease; disease progression is attributable to chronic diffuse neurodegenerative damage, a portion of which is caused by permanent focal damage. The colored boxes indicate typical eligibility criteria, as a range of EDSS scores, for recruitment into phase III trials. CIS clinically isolated syndrome, EDSS Expanded Disability Status Scale, MRI magnetic resonance imaging, $M S$ multiple sclerosis, $P P M S$ primary progressive MS, $R-S P M S$ relapsing secondary progressive MS, $R R$ relapsing-remitting, $R R M S$ relapsing-remitting MS, $S P M S$ secondary progressive MS a
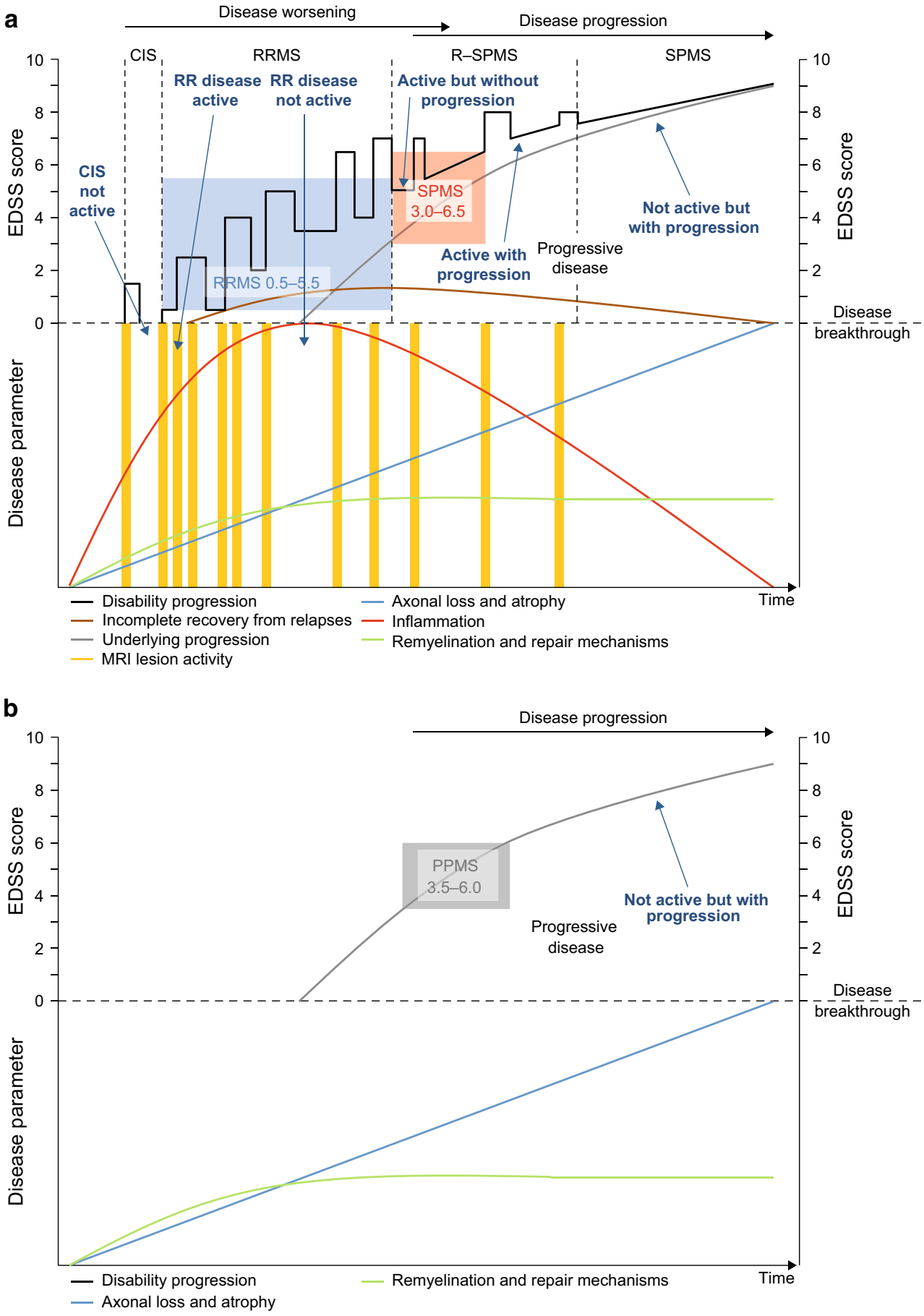
focal disease recedes $[105,109]$. In addition to permanent focal CNS damage, this diffuse neurodegeneration contributes to the long-term brain atrophy characteristic of disease progression.

Brain atrophy begins early in patients with MS [110], is one of the best predictors of long-term disability [111, 112] and correlates with worsening disability [113]. Analyses conducted post hoc in a population of patients with relapsing MS pooled from the three phase III trials of fingolimod [20-22] revealed a strengthening correlation between loss of brain volume and increase in EDSS score over 4 years [113]. During this period, the correlation between these parameters was also generally stronger in the group of patients with 6-month CDP than in the overall analysis population; consistent with these findings, the average increase in EDSS score over 4 years was greatest in the quartile of patients with the most brain volume loss. In the same set of analyses, significant correlations were also seen between brain volume at baseline and both EDSS score and T2 lesion volume, the former correlation supporting an association between loss of brain volume and accrual of disability before enrolment, and the latter correlation supporting an association between accumulated inflammatory focal CNS damage and brain atrophy [113]. These relationships between CNS damage and disability progression emphasise the need to initiate treatment to arrest focal inflammatory and diffuse neurodegenerative processes as early as possible. Although there are both procedural and methodological challenges in conducting routine monitoring of brain volume in patients with MS, these challenges should be tackled because treatment to reduce brain volume loss has been shown to correlate with beneficial effects on disability [114]. The effect of different MS DMTs on brain atrophy is reviewed elsewhere [115].

The evolution of the pathophysiology of MS during the disease course serves to emphasise the difficulty in comparing treatment effects, and confounds long-term extrapolation of effects seen during a 2- or 3-year clinical trial. Furthermore, changes in EDSS score tend to be modest over such a period, and long-term follow-up data, which might corroborate short-term effects on disability, are currently unavailable for many DMTs; the outcomes of several ongoing phase III trial extensions will be interesting. Beyond clinical trials, statistical modelling of realworld data offers a further means to assess the benefits of different treatments. Although still relatively short-term, a recent MS registry analysis of 3326 propensity-matched patients with a median follow-up time of 3.7 years found no difference among IFN beta therapies and GA in terms of 12-month CDP [116].

Despite great progress in the treatment of patients with relapsing MS, there remains an urgent need for drugs that modify the progressive disease course. From the patient's perspective, physical and cognitive deterioration is probably the greatest concern. It is therefore important that clinical and paraclinical measures that accurately predict and track disease worsening and progression continue to be optimized and standardized to inform prescribing decisions.

\section{Conclusions}

In relapsing MS, increased numbers of approved DMTs give clinicians much greater scope than was possible only 5 years ago to select therapy options that their patients tolerate and which are likely to slow disability progression. Treatment options for patients with progressive MS remain scant, but immunomodulatory therapies may be effective in certain patient phenotypes. Challenges remain in standardizing how the efficacy of new and existing treatments is assessed, and assessment of subclinical disease as well as of relapses and disability progression should become part of routine disease monitoring. For the best outcomes in relapsing MS, evidence is accumulating that the most effective treatments should be used early in the disease course to reduce inflammatory disease, slow the accumulation of CNS damage and atrophy, and thereby delay the accrual of disability.

Acknowledgments HW has received compensation for serving on scientific advisory boards/steering committees for Bayer Healthcare, Biogen Idec, Genzyme, Merck Serono, Novartis and Sanofi Aventis; has received speaker's honoraria and travel support from Bayer Vital GmbH, Bayer Schering AG, Biogen Idec, CSL Behring, Fresenius Medical Care, Genzyme, GlaxoSmithKline, GW Pharmaceuticals, Lundbeck, Merck Serono, Omniamed, Novartis and Sanofi Aventis; has received compensation as a consultant from Biogen Idec, Merck Serono, Novartis and Sanofi Aventis and has received research support from Bayer Vital GmbH, Biogen Idec, Genzyme, Merck Serono, Novartis, Sanofi Aventis Germany and Sanofi US.

SGM has received honoraria for lecturing and travel expenses for attending meetings and has received financial research support from Bayer, Bayer Schering, Biogen Idec, Genzyme, Merck Serono, MSD, Novartis, Novo Nordisk, Sanofi-Aventis and Teva.

The authors would like to acknowledge Jeremy Bright from Oxford PharmaGenesis, who provided editorial support (assistance in drafting and editing of the manuscript text, figures, and tables, as directed by authors, data checking, and assistance with the submission process) with funding from Novartis Pharma AG. This was the only funding provided for the development of this article.

Open Access This article is distributed under the terms of the Creative Commons Attribution-NonCommercial 4.0 International License (http://creativecommons.org/licenses/by-nc/4.0/), which permits any noncommercial use, distribution, and reproduction in any medium, provided you give appropriate credit to the original author(s) and the source, provide a link to the Creative Commons license, and indicate if changes were made. 


\section{Glossary of Trials Listed}

ACCLAIM

ADVANCE

AFFIRM

ALLEGRO

ASCEND

ATAMS

ATTAIN

BENEFIT

BEYOND

CARE-MS

CHAMPS

CHOLINE

CLARITY

CombiRx
A Cooperative Clinical Study of Abatacept in Multiple Sclerosis Efficacy and Safety Study of Peginterferon Beta-1a in Participants with Relapsing Multiple Sclerosis

Natalizumab Safety and Efficacy in Relapsing Remitting Multiple Sclerosis Assessment of Oral Laquinimod in Preventing Progression in Multiple Sclerosis

A Clinical Study of the Efficacy of Natalizumab on Reducing Disability Progression in Participants with Secondary Progressive Multiple Sclerosis

Atacicept in Multiple Sclerosis, Phase II

Long-Term Safety and Efficacy Study of BIIB017 (PEGylated Interferon Beta-1a)

Betaferon/Betaseron in Newly Emerging Multiple Sclerosis for Initial Treatment

Betaferon/Betaseron Efficacy Yielding Outcomes of a New Dose in Multiple Sclerosis (MS) Patients

Benefit-Risk Assessment of Avonex and Laquinimod

Comparison of Alemtuzumab and Rebif Efficacy in Multiple Sclerosis

Controlled High-Risk Subjects Avonex Multiple Sclerosis Prevention Study

A Multicentre Study of the Efficacy and Safety of Supplementary Treatment with Cholecalciferol in Patients with Relapsing Multiple Sclerosis Treated with Subcutaneous Interferon Beta-1a $44 \mu \mathrm{g}$ 3 Times Weekly

Cladribine Tablets Treating

Multiple Sclerosis Orally

Combination Therapy in

Patients with Relapsing-

Remitting Multiple Sclerosis
CONFIRM

CONTAIN

DEFINE

EVIDENCE

FLORIMS

FREEDOMS

GALA

GATEWAY II

IFNB

IMPACT

IMPROVE

INCOMIN

INFORMS

MAESTRO

Memantine-MS

MIMS

MS-SPI
Comparator and an Oral Fumarate in RelapsingRemitting Multiple Sclerosis Dietary Supplement of Curcumin in Subjects with Active Relapsing Multiple Sclerosis Treated with Subcutaneous Interferon Beta 1a Efficacy and Safety of BIIB019 (Daclizumab High Yield Process) Versus Interferon $\beta$ 1a in Participants with RelapsingRemitting Multiple Sclerosis

Determination of the Efficacy and Safety of Oral Fumarate in Relapsing-Remitting Multiple Sclerosis

Evidence of Interferon DoseResponse European North American Comparative Efficacy Flupirtine as Oral Treatment in Multiple Sclerosis

FTY720 Research Evaluating Effects of Daily Oral Therapy in Multiple Sclerosis

Glatiramer Acetate Lowfrequency Administration

Comparison of Rituximab Induction Therapy Followed by Glatiramer Acetate Therapy to Glatiramer Acetate Monotherapy for MS

Interferon Beta-1b Study

International MS Secondary Progressive Avonex Controlled Trial

Investigating MRI Parameters with $\quad$ Rebif $^{\circledR} \quad$ Improved Formulation

Independent Comparison of Interferons

Investigating FTY720 Oral in Primary Progressive MS

A Study for Patients with Secondary Progressive Multiple Sclerosis

Memantine Therapy for Multiple Sclerosis

Mitoxantrone in Multiple Sclerosis Study

Effect of MD1003 in Spinal Progressive Multiple Sclerosis 
MS-STAT

OFAMS

OLYMPUS

ORACLE MS

PreCISe

PROMiSe

PRISMS

RECLAIM

RECYCLINE

REFLEX

REGARD

SELECTED

SENTINEL

SOLAR
Investigation of Simvastatin in Secondary Progressive Multiple Sclerosis

$\omega-3$ Fatty Acid Treatment in Multiple Sclerosis

A Study to Evaluate the Safety and Efficacy of Rituximab in Adults with Primary Progressive Multiple Sclerosis Oral cladribine for early MS

Early Glatiramer Acetate Treatment in Delaying Conversion to Clinically Definite Multiple Sclerosis in Subjects Presenting with a Clinically Isolated Syndrome Glatiramer Acetate in Primary Progressive Multiple Sclerosis Prevention of Relapses and Disability by Interferon Beta1a Subcutaneously in Multiple Sclerosis

Efficacy Study of Adrenocorticotropin Hormone to Treat Multiple Sclerosis (MS) Relapses After Subresponding to an Initial 3 Day Course of Intravenous (IV) Methylprednisolone

Minocycline as Add-on to Interferon Beta-1a [IFN Beta1a] $\left(\right.$ Rebif $\left.^{\circledR}\right)$ in RelapsingRemitting Multiple Sclerosis

Rebif Flexible dosing in early MS

Rebif vs Glatiramer Acetate in Relapsing MS Disease

Safety and Efficacy Extension Study of Daclizumab High Yield Process (DAC HYP) (BIIB019) in Participants Who Have Completed Study 205MS202 (NCT00870740) to Treat Relapsing Remitting Multiple Sclerosis

Safety and Efficacy of Natalizumab in Combination with Interferon Beta-1a in Patients with RelapsingRemitting Multiple Sclerosis Supplementation of VigantOL ${ }^{\circledR}$ Oil Versus Placebo as Add-on

in Patients with Relapsing Remitting Multiple Sclerosis Receiving Rebif ${ }^{\circledR}$ Treatment

SPECTRIMS

STRATA

SUPREMES

SURPASS

SWABIMS

SYNERGY

TEMSO

TENERE

TERACLES

TIME-MS

TOFINGO

TOPIC

TOWER

TRANSFORMS
Secondary Progressive Efficacy Clinical Trial of Recombinant Interferon-beta-1a in MS

Natalizumab (Tysabri) ReInitiation of Dosing

Sunphenon in Progressive Forms of Multiple Sclerosis

Study Evaluating Rebif, Copaxone, and Tysabri for Active Multiple Sclerosis

Swiss Atorvastatin and Interferon Beta-1b trial In Multiple Sclerosis

Study to Assess the Efficacy, Safety, Tolerability, and Pharmacokinetics of BIIB033 in Participants with Relapsing Forms of Multiple Sclerosis When Used Concurrently with Avonex

Teriflunomide Multiple Sclerosis Oral

Teriflunomide and Rebif ${ }^{\circledR}$

Efficacy and Safety of Teriflunomide in Patients with Relapsing Multiple Sclerosis and Treated with Interferonbeta

Safety Study of Combination Therapy with Intramuscular Avonex and Oral Cellcept in Patients with Multiple Sclerosis Disease Control and Safety in Patients with Relapsing Remitting Multiple Sclerosis (RRMS) Switching From Natalizumab to Fingolimod

Oral Teriflunomide for Patients with a First Clinical Episode Suggestive of Multiple Sclerosis Teriflunomide Oral in People with Relapsing Multiple Sclerosis

Trial Assessing Injectable Interferon versus FTY720 Oral in Relapsing-Remitting Multiple Sclerosis 


\section{References}

1. Kurtzke JF. A new scale for evaluating disability in multiple sclerosis. Neurology. 1955;5:580-3.

2. Kurtzke JF. Rating neurologic impairment in multiple sclerosis: an expanded disability status scale (EDSS). Neurology. 1983;33:1444-52.

3. Weinshenker BG, Bass B, Rice GP, et al. The natural history of multiple sclerosis: a geographically based study. I. Clinical course and disability. Brain. 1989;112(Pt 1):133-46.

4. Pfleger CC, Flachs EM, Koch-Henriksen N. Social consequences of multiple sclerosis (1): early pension and temporary unemployment-a historical prospective cohort study. Mult Scler. 2010;16:121-6.

5. Kobelt G, Berg J, Lindgren P, et al. Costs and quality of life of patients with multiple sclerosis in Europe. J Neurol Neurosurg Psychiatry. 2006;77:918-26.

6. Cohen JA, Reingold SC, Polman $\mathrm{CH}$, et al. Disability outcome measures in multiple sclerosis clinical trials: current status and future prospects. Lancet Neurol. 2012;11:467-76.

7. Amato MP, Fratiglioni L, Groppi C, et al. Interrater reliability in assessing functional systems and disability on the Kurtzke scale in multiple sclerosis. Arch Neurol. 1988;45:746-8.

8. Francis DA, Bain P, Swan AV, et al. An assessment of disability rating scales used in multiple sclerosis. Arch Neurol. 1991;48:299-301.

9. Goodkin DE, Cookfair D, Wende K, et al. Inter- and intrarater scoring agreement using grades 1.0 to 3.5 of the Kurtzke Expanded Disability Status Scale (EDSS). Multiple Sclerosis Collaborative Research Group. Neurology. 1992;42:859-63.

10. Noseworthy JH, Vandervoort MK, Wong CJ, et al. Interrater variability with the Expanded Disability Status Scale (EDSS) and Functional Systems (FS) in a multiple sclerosis clinical trial. The Canadian Cooperation MS Study Group. Neurology. 1990;40:971-5.

11. Weinshenker BG, Rice GP, Noseworthy JH, et al. The natural history of multiple sclerosis: a geographically based study. 4 . Applications to planning and interpretation of clinical therapeutic trials. Brain. 1991;114(Pt 2):1057-67.

12. Fischer JS, Rudick RA, Cutter GR, et al. The Multiple Sclerosis Functional Composite Measure (MSFC): an integrated approach to MS clinical outcome assessment. National MS Society Clinical Outcomes Assessment Task Force. Mult Scler. 1999;5:244-50.

13. Cutter GR, Baier ML, Rudick RA, et al. Development of a multiple sclerosis functional composite as a clinical trial outcome measure. Brain. 1999;122(Pt 5):871-82.

14. Meyer-Moock S, Feng YS, Maeurer M, et al. Systematic literature review and validity evaluation of the Expanded Disability Status Scale (EDSS) and the Multiple Sclerosis Functional Composite (MSFC) in patients with multiple sclerosis. BMC Neurol. 2014;14:58.

15. Meuth SG, Bittner S, Ulzheimer JC, et al. Therapeutic approaches to multiple sclerosis: an update on failed, interrupted, or inconclusive trials of neuroprotective and alternative treatment strategies. BioDrugs. 2010;24:317-30.

16. Ulzheimer JC, Meuth SG, Bittner S, et al. Therapeutic approaches to multiple sclerosis: an update on failed, interrupted, or inconclusive trials of immunomodulatory treatment strategies. BioDrugs. 2010;24:249-74.

17. European Medicines Agency. Guideline on clinical investigation of medicinal products for the treatment of Multiple Sclerosis. 2015. http://www.ema.europa.eu/docs/en_GB/document_library/ Scientific_guideline/2015/03/WC500185161.pdf. Accessed 08 Apr 2015.
18. National Institute for Health and Care Excellence (NICE). Dimethyl fumarate for treating relapsing-remitting multiple sclerosis. NICE technology appraisal guidance 320. 2014. https://www.nice.org.uk/guidance/ta320/resources/guidancedimethyl-fumarate-for-treating-relapsingremitting-multiplesclerosis-pdf. Accessed 24 Feb 2015.

19. Lublin FD, Reingold SC, Cohen JA, et al. Defining the clinical course of multiple sclerosis: the 2013 revisions. Neurology. 2014;83:278-86.

20. Kappos L, Radue EW, O'Connor P, et al. A placebo-controlled trial of oral fingolimod in relapsing multiple sclerosis. N Engl J Med. 2010;362:387-401.

21. Calabresi PA, Radue EW, Goodin D, et al. Safety and efficacy of fingolimod in patients with relapsing-remitting multiple sclerosis (FREEDOMS II): a double-blind, randomised, placebo-controlled, phase 3 trial. Lancet Neurol. 2014;13:545-56.

22. Cohen JA, Barkhof F, Comi G, et al. Oral fingolimod or intramuscular interferon for relapsing multiple sclerosis. $\mathrm{N}$ Engl $\mathrm{J}$ Med. 2010;362:402-15.

23. Novartis Pharmaceuticals Corporation. Prescribing information-Gilenya ${ }^{\circledR}$. 2014. http://www.accessdata.fda.gov/drugsatfda docs/label/2014/022527s009lbl.pdf. Accessed 24 Feb 2015.

24. Novartis Europharm Limited. Summary of product characteristics_Gilenya ${ }^{\circledR}$. 2014. http://www.ema.europa.eu/docs/en_GB/ document_library/EPAR_-_Product_Information/human/002202/ WC500104528.pdf. Accessed 24 Feb 2015.

25. Sanofi-Aventis Group. Summary of Product Characteristics Aubagio $^{\circledR}$. 2014. http://www.ema.europa.eu/docs/en_GB/ document_library/EPAR_-_Product_Information/human/002514/ WC500148682.pdf. Accessed 24 Feb 2015.

26. Genzyme Corporation, a Sanofi company. Prescribing information-Aubagio ${ }^{\circledR}$. 2014. http://products.sanofi.us/aubagio/ aubagio.pdf. Accessed 26 Mar 2015.

27. O'Connor P, Wolinsky JS, Confavreux C, et al. Randomized trial of oral teriflunomide for relapsing multiple sclerosis. N Engl J Med. 2011;365:1293-303.

28. Confavreux C, O'Connor P, Comi G, et al. Oral teriflunomide for patients with relapsing multiple sclerosis (TOWER): a randomised, double-blind, placebo-controlled, phase 3 trial. Lancet Neurol. 2014;13:247-56.

29. Miller AE, Wolinsky JS, Kappos L, et al. Oral teriflunomide for patients with a first clinical episode suggestive of multiple sclerosis (TOPIC): a randomised, double-blind, placebo-controlled, phase 3 trial. Lancet Neurol. 2014;13:977-86.

30. European Medicines Agency. Assessment report-Aubagio ${ }^{\circledR}$. 2013. http://www.ema.europa.eu/docs/en_GB/document_library/ EPAR_-_Public_assessment_report/human/002514/WC500148684. pdf. Accessed 24 Feb 2015.

31. Vermersch P, Czlonkowska A, Grimaldi LM, et al. Teriflunomide versus subcutaneous interferon beta-1a in patients with relapsing multiple sclerosis: a randomised, controlled phase 3 trial. Mult Scler. 2014;20:705-16.

32. Biogen Idec Limited. Summary of product characteristicsTecfidera ${ }^{\circledR}$. 2014. http://www.ema.europa.eu/docs/en_GB/ document_library/EPAR_-_Product_Information/human/002601/ WC500162069.pdf. Accessed 24 Feb 2015.

33. Biogen Inc. Prescribing information-Tecfidera ${ }^{\circledR}$. 2014. https:// www.tecfidera.com/pdfs/full-prescribing-information.pdf. Accessed 26 March 2015.

34. Fox RJ, Miller DH, Phillips JT, et al. Placebo-controlled phase 3 study of oral BG-12 or glatiramer in multiple sclerosis. N Engl J Med. 2012;367:1087-97.

35. Gold R, Kappos L, Arnold DL, et al. Placebo-controlled phase 3 study of oral BG-12 for relapsing multiple sclerosis. N Engl J Med. 2012;367:1098-107. 
36. European Medicines Agency. Assessment report-Tecfidera ${ }^{\circledR}$. 2014. http://www.ema.europa.eu/docs/en_GB/document_library/ EPAR_-_Public_assessment_report/human/002601/WC500162070. pdf. Accessed 24 Feb 2015.

37. Comi G, Jeffery D, Kappos L, et al. Placebo-controlled trial of oral laquinimod for multiple sclerosis. N Engl J Med. 2012;366:1000-9.

38. Vollmer TL, Sorensen PS, Selmaj K, et al. A randomized placebo-controlled phase III trial of oral laquinimod for multiple sclerosis. J Neurol. 2014;261:773-83.

39. Giovannoni G, Comi G, Cook S, et al. A placebo-controlled trial of oral cladribine for relapsing multiple sclerosis. N Engl J Med. 2010;362:416-26.

40. Leist TP, Comi G, Cree BA, et al. Effect of oral cladribine on time to conversion to clinically definite multiple sclerosis in patients with a first demyelinating event (ORACLE MS): a phase 3 randomised trial. Lancet Neurol. 2014;13:257-67.

41. European Medicines Agency. Withdrawal of the marketing authorisation application for Movectro (cladribine). 2011. http:// www.ema.europa.eu/docs/en_GB/document_library/Medicine_QA/ 2011/02/WC500102304.pdf. Accessed 24 Feb 2015.

42. Massacesi L, Tramacere I, Amoroso S, et al. Azathioprine versus beta interferons for relapsing-remitting multiple sclerosis: a multicentre randomized non-inferiority trial. PLoS One. 2014;9:e113371.

43. Genzyme Therapeutics Limited. Summary of product characteristics - Lemtrada ${ }^{\circledR}$. 2014. http://www.ema.europa.eu/docs/ en_GB/document_library/EPAR_-_Product_Information/human/ 003718/WC500150521.pdf. Accessed 24 Feb 2015.

44. Genzyme Corporation. Prescribing information-Lemtrada ${ }^{\circledR}$. 2014. http://products.sanofi.us/lemtrada/lemtrada.pdf. Accessed 24 Feb 2015.

45. Cohen JA, Coles AJ, Arnold DL, et al. Alemtuzumab versus interferon beta $1 \mathrm{a}$ as first-line treatment for patients with relapsing-remitting multiple sclerosis: a randomised controlled phase 3 trial. Lancet. 2012;380:1819-28.

46. Coles AJ, Twyman CL, Arnold DL, et al. Alemtuzumab for patients with relapsing multiple sclerosis after disease-modifying therapy: a randomised controlled phase 3 trial. Lancet. 2012;380:1829-39.

47. Biogen Inc. Prescribing information-Tysabri ${ }^{\circledR}$. 2014. http:// www.tysabri.com/prescribingInfo. Accessed 26 March 2015.

48. Biogen Idec Limited. Summary of product characteristicsTysabri $^{\circledR}$. 2014. http://www.ema.europa.eu/docs/en_GB/ document_library/EPAR_-_Product_Information/human/000603/ WC500044686.pdf. Accessed 24 Feb 2015.

49. Polman CH, O'Connor PW, Havrdova E, et al. A randomized, placebo-controlled trial of natalizumab for relapsing multiple sclerosis. N Engl J Med. 2006;354:899-910.

50. Rudick RA, Stuart WH, Calabresi PA, et al. Natalizumab plus interferon beta-1a for relapsing multiple sclerosis. $\mathrm{N}$ Engl J Med. 2006;354:911-23.

51. EMD Serono. Prescribing information-Novantrone ${ }^{\circledR} .2012$. http://www.accessdata.fda.gov/drugsatfda_docs/label/2012/ 019297s035lbl.pdf. Accessed 24 Feb 2015.

52. Edan G, Miller D, Clanet M, et al. Therapeutic effect of mitoxantrone combined with methylprednisolone in multiple sclerosis: a randomised multicentre study of active disease using MRI and clinical criteria. J Neurol Neurosurg Psychiatry. 1997;62:112-8.

53. Millefiorini E, Gasperini C, Pozzilli C, et al. Randomized placebo-controlled trial of mitoxantrone in relapsing-remitting multiple sclerosis: 24-month clinical and MRI outcome. J Neurol. 1997;244:153-9.

54. Hartung HP, Gonsette R, Konig N, et al. Mitoxantrone in progressive multiple sclerosis: a placebo-controlled, double-blind, randomised, multicentre trial. Lancet. 2002;360:2018-25.
55. Edan G, Comi G, Le Page E, et al. Mitoxantrone prior to interferon beta- $1 \mathrm{~b}$ in aggressive relapsing multiple sclerosis: a 3-year randomised trial. $\mathrm{J}$ Neurol Neurosurg Psychiatry. 2011;82:1344-50.

56. TEVA Pharmaceuticals USA, Inc. Prescribing informationCopaxone $^{\circledR}$. 2014. http://www.accessdata.fda.gov/drugsatfda_ docs/label/2009/020622s057lbl.pdf. Accessed 26 March 2015.

57. Teva Pharmaceuticals Limited. Summary of product characteristics-Copaxone ${ }^{\circledR}$. 2014. https://www.medicines.org.uk/emc/ medicine/17516. Accessed 24 Feb 2015.

58. Khan O, Rieckmann P, Boyko A, et al. Three times weekly glatiramer acetate in relapsing-remitting multiple sclerosis. Ann Neurol. 2013;73:705-13.

59. Comi G, Martinelli V, Rodegher M, et al. Effect of glatiramer acetate on conversion to clinically definite multiple sclerosis in patients with clinically isolated syndrome (PreCISe study): a randomised, double-blind, placebo-controlled trial. Lancet. 2009;374:1503-11.

60. Mikol DD, Barkhof F, Chang P, et al. Comparison of subcutaneous interferon beta-1a with glatiramer acetate in patients with relapsing multiple sclerosis (the REbif vs Glatiramer Acetate in Relapsing MS Disease [REGARD] study): a multicentre, randomised, parallel, open-label trial. Lancet Neurol. 2008; 7:903-14.

61. O'Connor P, Filippi M, Arnason B, et al. 250 microg or 500 microg interferon beta- $1 \mathrm{~b}$ versus $20 \mathrm{mg}$ glatiramer acetate in relapsing-remitting multiple sclerosis: a prospective, randomised, multicentre study. Lancet Neurol. 2009;8:889-97.

62. Lublin FD, Cofield SS, Cutter GR, et al. Randomized study combining interferon and glatiramer acetate in multiple sclerosis. Ann Neurol. 2013;73:327-40.

63. Center for Drug Evaluation and Research. Approval letter-interferon beta-1b. 1993. http://www.accessdata.fda.gov/drugsatfda docs/nda/pre96/103471s0000_APPROV.pdf. Accessed 24 Feb 2015.

64. European Medicines Agency. Betaferon ${ }^{\circledR}$-authorisation details. 2013. http://www.ema.europa.eu/ema/index.jsp?curl= pages/medicines/human/medicines/000081/human_med_000673. jsp\&mid=WC0b01ac058001d124. Accessed 26 March 2015.

65. Biogen Inc. Prescribing information-Avonex ${ }^{\circledR}$. 2014. http:// www.avonex.com/pdfs/Avonex_Prescribing_Information.pdf Accessed 26 March 2015.

66. Biogen Idec Limited. Summary of product characteristicsAvonex ${ }^{\circledR}$. 2014. http://www.ema.europa.eu/docs/en_GB/ document_library/EPAR_-_Product_Information/human/000102/ WC500029425.pdf. Accessed 24 Feb 2015.

67. EMD Serono Inc. Prescribing information-Rebif ${ }^{\circledR} .2014$. http:// emdserono.com/cmg.emdserono_us/en/images/Rebif\%20PI_Jun 2014_tcm115_19765.pdf?Version=. Accessed 26 March 2015.

68. Merck Serono Europe Limited. Summary of product characteristics—Rebif $^{\circledR}$. 2014. http://www.ema.europa.eu/docs/en_GB/ document_library/EPAR_-_Product_Information/human/000136/ WC500048681.pdf. Accessed 24 Feb 2015.

69. Novartis Corporation Inc. Prescribing information-Extavia ${ }^{\circledR}$. 2014. http://www.pharma.us.novartis.com/product/pi/pdf/extavia. pdf. Accessed 26 March 2015.

70. Novartis Europharm Limited. Summary of product characteristics-Extavia ${ }^{\circledR}$. 2014. http://www.ema.europa.eu/docs/en_GB/ document_library/EPAR_-_Product_Information/human/000933/ WC500034701.pdf. Accessed 24 Feb 2015.

71. Bayer HealthCare Pharmaceuticals. Prescribing informationBetaseron ${ }^{\circledR}$. 2014. http://labeling.bayerhealthcare.com/html/ products/pi/Betaseron_PI.pdf. Accessed 26 March 2015.

72. Bayer Pharma AG. Summary of product characteristicsBetaferon $^{\circledR}$. 2014. http://www.ema.europa.eu/docs/en_GB/ document_library/EPAR_-_Product_Information/human/000081/ WC500053225.pdf. Accessed 24 Feb 2015. 
73. Jacobs LD, Cookfair DL, Rudick RA, et al. Intramuscular interferon beta-1a for disease progression in relapsing multiple sclerosis. The Multiple Sclerosis Collaborative Research Group (MSCRG). Ann Neurol. 1996;39:285-94.

74. Jacobs LD, Beck RW, Simon JH, et al. Intramuscular interferon beta-1a therapy initiated during a first demyelinating event in multiple sclerosis. CHAMPS Study Group. N Engl J Med. 2000;343:898-904.

75. Randomised double-blind placebo-controlled study of interferon beta-1a in relapsing/remitting multiple sclerosis. PRISMS (Prevention of Relapses and Disability by Interferon beta-1a Subcutaneously in Multiple Sclerosis) Study Group. Lancet. 1998;352:1498-504.

76. Panitch H, Goodin DS, Francis G, et al. Randomized, comparative study of interferon beta-1a treatment regimens in MS: the EVIDENCE trial. Neurology. 2002;59:1496-506.

77. Schwid SR, Panitch HS. Full results of the Evidence of Interferon Dose-Response-European North American Comparative Efficacy (EVIDENCE) study: a multicenter, randomized, assessor-blinded comparison of low-dose weekly versus highdose, high-frequency interferon beta-1a for relapsing multiple sclerosis. Clin Ther. 2007;29:2031-48.

78. De Stefano N, Curtin F, Stubinski B, et al. Rapid benefits of a new formulation of subcutaneous interferon beta-1a in relapsing-remitting multiple sclerosis. Mult Scler. 2010;16:888-92.

79. Comi G, De Stefano N, Freedman MS, et al. Comparison of two dosing frequencies of subcutaneous interferon beta-1a in patients with a first clinical demyelinating event suggestive of multiple sclerosis (REFLEX): a phase 3 randomised controlled trial. Lancet Neurol. 2012;11:33-41.

80. Interferon beta- $1 \mathrm{~b}$ is effective in relapsing-remitting multiple sclerosis. I. Clinical results of a multicenter, randomized, double-blind, placebo-controlled trial. The IFNB Multiple Sclerosis Study Group. Neurology. 1993;43:655-61.

81. Kappos L, Polman CH, Freedman MS, et al. Treatment with interferon beta- $1 \mathrm{~b}$ delays conversion to clinically definite and McDonald MS in patients with clinically isolated syndromes. Neurology. 2006;67:1242-9.

82. Durelli L, Verdun E, Barbero P, et al. Every-other-day interferon beta-1b versus once-weekly interferon beta-1a for multiple sclerosis: results of a 2-year prospective randomised multicentre study (INCOMIN). Lancet. 2002;359:1453-60.

83. Calabresi PA, Kieseier BC, Arnold DL, et al. Pegylated interferon beta-1a for relapsing-remitting multiple sclerosis (ADVANCE): a randomised, phase 3, double-blind study. Lancet Neurol. 2014;13:657-65.

84. Biogen Idec Limited. Summary of product characteristicsPlegridy ${ }^{\circledR}$. 2014. http://www.ema.europa.eu/docs/en_GB/ document_library/EPAR__Product_Information/human/002827/ WC500170302.pdf. Accessed 24 Feb 2015.

85. Kieseier BC, Arnold DL, Balcer LJ, et al. Peginterferon beta-1a in multiple sclerosis: 2-year results from ADVANCE. Mult Scler. 2014. doi:10.1177/1352458514557986.

86. Edan G, Kappos L, Montalban X, et al. Long-term impact of interferon beta-1b in patients with CIS: 8-year follow-up of BENEFIT. J Neurol Neurosurg Psychiatry. 2014;85:1183-9.

87. Kappos L, Selmaj K, Arnold DL, et al. Primary results of DECIDE: a randomized, double-blind, double-dummy, activecontrolled trial of daclizumab HYP vs. Interferon $\beta$-1a in RRMS patients. Mult Scler. 2014;20(S1):38.

88. Biogen Idec Limited. Biogen Idec and AbbVie announce positive top-line results from phase 3 study investigating daclizumab high-yield process in multiple sclerosis. 2014. http://www. biogenidec.com/press_release_details.aspx?ID=14712\&Action= $1 \&$ NewsId=2358\&M=NewsV2\&PID=61997. Accessed 24 Feb 2015.
89. Beutler E, Sipe JC, Romine JS, et al. The treatment of chronic progressive multiple sclerosis with cladribine. Proc Natl Acad Sci USA. 1996;93:1716-20.

90. Rice GP, Filippi M, Comi G. Cladribine and progressive MS: clinical and MRI outcomes of a multicenter controlled trial. Cladribine MRI Study Group. Neurology. 2000;54:1145-55.

91. Hawker K, O'Connor P, Freedman MS, et al. Rituximab in patients with primary progressive multiple sclerosis: results of a randomized double-blind placebo-controlled multicenter trial. Ann Neurol. 2009;66:460-71.

92. Freedman MS, Bar-Or A, Oger J, et al. A phase III study evaluating the efficacy and safety of MBP8298 in secondary progressive MS. Neurology. 2011;77:1551-60.

93. Pohlau D, Przuntek H, Sailer M, et al. Intravenous immunoglobulin in primary and secondary chronic progressive multiple sclerosis: a randomized placebo controlled multicentre study. Mult Scler. 2007;13:1107-17.

94. Placebo-controlled multicentre randomised trial of interferon beta- $1 \mathrm{~b}$ in treatment of secondary progressive multiple sclerosis. European Study Group on interferon beta-1b in secondary progressive MS. Lancet. 1998;352:1491-7.

95. Panitch H, Miller A, Paty D, et al. Interferon beta-1b in secondary progressive MS: results from a 3-year controlled study. Neurology. 2004;63:1788-95.

96. Kappos L, Weinshenker B, Pozzilli C, et al. Interferon beta-1b in secondary progressive MS: a combined analysis of the two trials. Neurology. 2004;63:1779-87.

97. Montalban X, Sastre-Garriga J, Tintore M, et al. A single-center, randomized, double-blind, placebo-controlled study of interferon beta- $1 \mathrm{~b}$ on primary progressive and transitional multiple sclerosis. Mult Scler. 2009;15:1195-205.

98. Secondary Progressive Efficacy Clinical Trial of Recombinant Interferon-Beta-1a in MS (SPECTRIMS) Study Group. Randomized controlled trial of interferon- beta-1a in secondary progressive MS: Clinical results. Neurology. 2001;56:1496-504.

99. Andersen O, Elovaara I, Farkkila M, et al. Multicentre, randomised, double blind, placebo controlled, phase III study of weekly, low dose, subcutaneous interferon beta-1a in secondary progressive multiple sclerosis. J Neurol Neurosurg Psychiatry. 2004;75:706-10.

100. Leary SM, Miller DH, Stevenson VL, et al. Interferon beta-1a in primary progressive MS: an exploratory, randomized, controlled trial. Neurology. 2003;60:44-51.

101. Cohen JA, Cutter GR, Fischer JS, et al. Benefit of interferon beta-1a on MSFC progression in secondary progressive MS. Neurology. 2002;59:679-87.

102. Wolinsky JS, Narayana PA, O'Connor P, et al. Glatiramer acetate in primary progressive multiple sclerosis: results of a multinational, multicenter, double-blind, placebo-controlled trial. Ann Neurol. 2007;61:14-24.

103. Novartis Pharma AG. Novartis provides update on fingolimod Phase III trial in primary progressive MS (PPMS). 2014. http:// www.novartis.com/newsroom/media-releases/en/2014/1875463. shtml. Accessed 26 March 2015.

104. Wiendl H, Hohlfeld R. Multiple sclerosis therapeutics: unexpected outcomes clouding undisputed successes. Neurology. 2009;72:1008-15.

105. Frischer JM, Bramow S, Dal-Bianco A, et al. The relation between inflammation and neurodegeneration in multiple sclerosis brains. Brain. 2009;132:1175-89.

106. Freedman MS. Multiple sclerosis therapeutic strategies: use second-line agents as first-line agents when time is of the essence. Neurol Clin Pract. 2011;1:66-8.

107. Stys PK, Zamponi GW, van Minnen J, et al. Will the real multiple sclerosis please stand up? Nat Rev Neurosci. 2012;13:507-14. 
108. Bjartmar C, Wujek JR, Trapp BD. Axonal loss in the pathology of MS: consequences for understanding the progressive phase of the disease. J Neurol Sci. 2003;206:165-71.

109. Kutzelnigg A, Lassmann H. Pathology of multiple sclerosis and related inflammatory demyelinating diseases. Handb Clin Neurol. 2014;122:15-58.

110. Bermel RA, Bakshi R. The measurement and clinical relevance of brain atrophy in multiple sclerosis. Lancet Neurol. 2006;5:158-70.

111. Jacobsen C, Hagemeier J, Myhr KM, et al. Brain atrophy and disability progression in multiple sclerosis patients: a 10-year followup study. J Neurol Neurosurg Psychiatry. 2014;85:1109-15.

112. Popescu V, Ran NC, Barkhof F, et al. Accurate GM atrophy quantification in MS using lesion-filling with co-registered 2D lesion masks. Neuroimage Clin. 2014;4:366-73.

113. Radue EW, Barkhof F, Kappos L, et al. Correlation between brain volume loss and clinical and MRI outcomes in multiple sclerosis. Neurology. 2015;84:784-93.

114. Sormani MP, Arnold DL, De Stefano N. Treatment effect on brain atrophy correlates with treatment effect on disability in multiple sclerosis. Ann Neurol. 2014;75:43-9.

115. De Stefano N, Airas L, Grigoriadis N, et al. Clinical relevance of brain volume measures in multiple sclerosis. CNS Drugs. 2014;28:147-56.

116. Kalincik T, Jokubaitis V, Izquierdo G, et al. Comparative effectiveness of glatiramer acetate and interferon beta formulations in relapsing-remitting multiple sclerosis.Mult Scler. 2014; doi:10.1177/1352458514559865.

117. Kappos L, Antel J, Comi G, et al. Oral fingolimod (FTY720) for relapsing multiple sclerosis. N Engl J Med. 2006;355:1124-40.

118. Saida T, Kikuchi S, Itoyama Y, et al. A randomized, controlled trial of fingolimod (FTY720) in Japanese patients with multiple sclerosis. Mult Scler. 2012;18:1269-77.

119. Kira J, Itoyama Y, Kikuchi S, et al. Fingolimod (FTY720) therapy in Japanese patients with relapsing multiple sclerosis over 12 months: results of a phase 2 observational extension. BMC Neurol. 2014;14:21.

120. O'Connor PW, Li D, Freedman MS, et al. A Phase II study of the safety and efficacy of teriflunomide in multiple sclerosis with relapses. Neurology. 2006;66:894-900.
121. Freedman MS, Wolinsky JS, Wamil B, et al. Teriflunomide added to interferon-beta in relapsing multiple sclerosis: a randomized phase II trial. Neurology. 2012;78:1877-85.

122. Remington GM, Treadaway K, Frohman T, et al. A one-year prospective, randomized, placebo-controlled, quadruple-blinded, phase II safety pilot trial of combination therapy with interferon beta-1a and mycophenolate mofetil in early relapsingremitting multiple sclerosis (TIME MS). Ther Adv Neurol Disord. 2010;3:3-13.

123. Kamm CP, El-Koussy M, Humpert S, et al. Atorvastatin added to interferon beta for relapsing multiple sclerosis: 12-month treatment extension of the randomized multicenter SWABIMS trial. PLoS One. 2014;9:e86663.

124. Torkildsen O, Wergeland S, Bakke S, et al. Omega-3 fatty acid treatment in multiple sclerosis (OFAMS Study): a randomized, double-blind, placebo-controlled trial. Arch Neurol. 2012;69: 1044-51.

125. Miller DH, Weber T, Grove R, et al. Firategrast for relapsing remitting multiple sclerosis: a phase 2, randomised, doubleblind, placebo-controlled trial. Lancet Neurol. 2012;11:131-9.

126. Coles AJ, Compston DA, Selmaj KW, et al. Alemtuzumab vs. interferon beta-1a in early multiple sclerosis. N Engl J Med. 2008;359:1786-801.

127. Segal BM, Constantinescu CS, Raychaudhuri A, et al. Repeated subcutaneous injections of IL12/23 p40 neutralising antibody, ustekinumab, in patients with relapsing-remitting multiple sclerosis: a phase II, double-blind, placebo-controlled, randomised, dose-ranging study. Lancet Neurol. 2008;7:796-804.

128. European Medicines Agency MA. Scientific discussionTysabri ${ }^{\circledR}$. 2007. http://www.ema.europa.eu/docs/en_GB/ document_library/EPAR_-_Scientific_Discussion/human/000603/ WC500044690.pdf. Accessed 24 Feb 2015.

129. Chataway J, Schuerer N, Alsanousi A, et al. Effect of high-dose simvastatin on brain atrophy and disability in secondary progressive multiple sclerosis (MS-STAT): a randomised, placebocontrolled, phase 2 trial. Lancet. 2014;383:2213-21.

130. Vermersch P, Benrabah R, Schmidt N, et al. Masitinib treatment in patients with progressive multiple sclerosis: a randomized pilot study. BMC Neurol. 2012;12:36. 